\title{
For the Lulz: Anonymous, Aesthetics, and Affect
}

\author{
Rodrigo Ferrada Stoehrel ${ }^{1}$, Simon Lindgren ${ }^{2}$
}

\author{
${ }^{1}$ Department of Culture and Media Studies, Umeå University, Umeå, Sweden, rodri- \\ go.ferrada@umu.se,http://umu.academia.edu/RodrigoFerradaStoehrel
}

${ }^{2}$ Department of Sociology, Umeå University, Umeå, Sweden. simon.lindgren@umu.se, www.simonlindgren.com

\begin{abstract}
This paper discusses the ways in which affect and the political aesthetics of Anonymous can be linked to possibilities of arousing affect, create unity and mobilise resistance; invite public participation in public affairs. In the culture of Anonymous, political resistance is not considered as limited to rational tactics nor in accordance with the principles of intellectual/cognitive "reason" (alone), but interplayed with "the lulz" - a specific kind of political passion - that works as an affective political force; capable of inspiring an alternative (radical) imaginary. In this context, the "lulz" and the aesthetics of Anonymous are reflected in strategies of engagement deployed to challenge the hegemonic discourses promoted by political economy. Following Mouffe (2013), we argue that there is no political equality (plurality) without conflict and without conflict no constructive political dialogue. In this line of argument, we are also influenced by the Spinozan perspective on affect as ability for action and change.
\end{abstract}

Keywords: Anonymous, Affect, Aesthetics, Hacktivism, Passion, Lulz, Social Media, Power, Surveillance, Resistance

\section{Introduction}

The focus of this paper is on different but connected areas of power - relating to things such as economic globalisation, surveillance, censorship/freedom, "terrorism" and/or specific military activity - visually represented through online media, and intentionally produced to inform a wide spectrum of individuals and interest groups about global and local social forms of injustice. Or more importantly, produced and distributed with the purpose of providing users with possibilities to engage, bodily and emotionally, in diverse ways: may it be through physical antiwar/anti-Wall Street protests or hacktivist tactics (e.g., DDoS attacks).

We examine a sample of videos, photographs and propaganda posters, produced and digitally distributed (2008-2013) by the fragmented body of activists united globally under the generic name of Anonymous. Analytically, we will draw upon Mouffe's thoughts on "antagonism" and "passion," Foucault's ideas on international citizenship and the (ethical) "right to intervene" (beyond liberal and formalized regimes of government), together with Sontag's notion of institutional political inertia and the Deleuzian/Spinozan perspective on affect as a capacity for action. ${ }^{1}$ The goal is to analyse the ways in which Anonymous systematically inspire (not only) a radical and social imaginary but also other direct forms of action that have potential societal effects.

One of the main features of Anonymous is that it sits at the intersection of a broad and multidimensional spectrum of political regions, methods, and narratives, but operates under a unifying and highly recognisable visual/symbolic order. In this context, as Coleman (2013a) notes, the act of hacking remains important, specifically when it comes to government classified data and/or detecting and publishing financial dishonesty by means of computer intrusion. However, hacking should be considered as only one strategy in a series of knowledge

\footnotetext{
${ }^{1}$ On "the art of governing" or "governmentality" see Foucault (1991; 2007), Nadesan (2008), Dean (2010), Bröckling, Krasmann, and Lemke (2011).
} 
processes. Above all, the body of Anonymous is rooted in an idea produced and distributed through a complex set of actions and relations between particles: hackers, artists, creative strategists, physical protesters, but also consumers. The viewers of Anonymous YouTube videos or graphics who distribute and share the message of Anonymous across the globe are, in this view, also producers (and part of the expanding community): consumers/producers who get inspired and inspire others.

The political messages coming from the Anonymous activists are, hence, largely symbolic. They are narrated and (audio)visually distributed through aesthetic means, such as propaganda posters with an intertextual and distinct graphic profile and/or videos with an elaborated and associative montage structure. Furthermore, these videos tend to follow a defined visual storyline and include a set of identifiable technical-dramaturgical components (music, stills, graphics and moving images and, often, a dramatic voiceover). This creative process the symbolic/visual conversion of "hacked" or "alternative" information into public knowledge - is the centre of our analysis.

The aim of this paper is not to suggest that Anonymous is the ultimate solution to the shortcomings and fissures of democracy. Instead, we want to map out empirically and discuss Anonymous's affective and aesthetic strategies and potential to influence the (inter)national conscience. We also look at its technological structure; i.e., how subversive grassroots activities take place and how they are coordinated via technological and communicative tactics. ${ }^{2}$

Moreover, the aesthetic-symbolic attributes of Anonymous, such as the (smiling) Guy Fawkes mask and the systematic references to popular culture, is also visible in Anonymous' propaganda posters and videos. Rather sophisticated and attractive, they succeed in influencing a public or subcultural group on the Internet that hardly attracted by the predominant news and information channels. Hence, Anonymous firstly breaks with the content mediated by traditional journalism by imparting a counter-narrative of current events. Secondly, due to its activist structure and prankish nature, Anonymous also breaks with the established ethics: the professional codes of mainstream journalism concerning the conventional methods and modes of expression; the way in which a specific investigation takes place and finally how they are framed (by hacking, leaking, "trolling," 3 etc.).

Against this background, the paper has three sub-objectives: (1) to map out the intersection between Anonymous hacking and visual political strategies, (2) to discuss the potential effects of Anonymous and hacker culture in relation to the political-economy of communication and (3) to discuss the way in which Anonymous practices are related to questions of affect, "the lulz," and political resistance.

\section{Affect and Antagonism}

Inspired by Spinoza (1982), we view (the power of) affect as related to the capacity to act and to convey (by increasing or diminishing ways) the power of activity or acting; to bring out change (cf. Spinoza ibid.; Deleuze, 1988; 1990). "Protest affect" or "political passion" in this sense, is understood as the passionate feeling of being part of, and empowered by, an alternative worldview, a community and/or a mix of actions that may give a heightened (intensive) sense of identity and meaning to one's life. In such actions, rational political strategies and affective responses such as "joy" and "rage" co-exist (cf. Goodwin, James and Polletta, 2001). According to Spinoza then, the affection of joy, specifically, can increase activity and the body's acting power $(1982,211)$.

\footnotetext{
${ }^{2}$ We argue that Anonymous more than thought about in isolation should be considered as an affective particle within a larger body-context of (whistleblower, hacker, visual) culture that furthermore connects to a wider (academic, political, journalistic, etc.) sphere and discussion of state-corporate security and political counternarratives. Following this line of reasoning, counter-power works as power; i.e., not coming from one big homogeneous block, but from a range of decentralised sources with the capacity to affect and be affected, by each other.

${ }^{3}$ Taking into account the roots of Anonymous in underground Internet popular culture, we suggest that the act of trolling can be regarded as a form of language or a lulzy/humorous mode of (offensive) expression that is used to destabilise the "opponent" but extended, here, into a political strategy.
} 
This kind of (protest) affect is regarded as a capacity to affect and be affected. In our context, this means a transition, a political self-consciousness able to be activated and with the ability to activate others. Affect is thus not a static subjective feature, but rather a "becomingintense" (Deleuze and Guattari, 1988, 256), basically, meaning intensive "ways of connecting, to others and to other situations" (where oneself, potentially at least, is transformed in the experience, see, Massumi in Zournazi, 2002, 214; Spinoza, 1982, 98). An example is Anonymous's claim that they are doing the things they do "for the lulz." This illustrates how their different forms of political resistance may be motivated by political ideas, but also via "joyful passions" and/or even personal enjoyment at the same time - all working as exalting (passionate) performances, potentially inspiring other ideas (imaginaries) or actions. ${ }^{4}$ That is, where strategies of enjoyment or the (forbidden) pleasures of Anonymous cannot be excluded from rational goals and political effects. ${ }^{5}$

It seems to us that in order to create public political debate and to mobilize social movements, hegemonic discourses as well as their channels of distribution need to be challenged in one way or another. It is only by pushing the established limits that people can provoke a discussion regarding the narratives surrounding their lives. However, the challenge of hegemonic discourse may not only be politically rational, but also emotionally and affectively subversive. As the lawyer and U.S. activist Staughton Lynd puts it: "History [...] might come about because Rosa Parks refused to go to the back of a bus, because four young men "sat in" at a segregated lunch counter, or because David Mitchell refused to be drafted for a war in Vietnam that he considered a war crime" $(2012,8)$.

As Lynd suggests, the history of resistance can be understood in terms of Williams's notion of the "structure of feeling" (1979). Williams considers emotions in relation to social/political processes (culture, class, history, etc.) and the structure of feeling as the lived (performative and sensorial) experience of them. He speaks of (re)constructing a "feeling much more than thought - a pattern of impulses, restraints, tones" $(1979,159){ }^{6}$ In this context, there is a feeling of political resistance (beyond, but not excluding cognition) that runs through history parallel to the one reframed in time by movements and actors such as Occupy Wall Street (cf. Lynd, ibid.), Anonymous, WikiLeaks, Assange, Manning, Hammond, Brown, Snowden, and others. The symbolic resistance and/or the counter-hegemonic actions connected to these political movements/actors are therefore neither necessarily bound to a particular political system, nor to traditional party politics, but rather to the development of the critical thought, in a reconsideration or re-evaluation of the democratic project as such (cf. Goodwin, James and Polletta, 2001; Kristeva, 1984).

This is, hence, similar to Laclau and Mouffe's thoughts on "antagonism" and/or the social/radical imaginary. The authors describe it as a form of "fantasmatic" (and radical) counter-discourse mobilised by "hope" or "passion" (motivated by the desire for social change by addressing the social imaginary of subjects), which they deem necessary to democracy as an ongoing project (instead of a static political system) re-evaluating itself in a dialogue with

\footnotetext{
${ }^{4}$ Enjoyment is here understood in a range of contexts: between personal, structural, moral, rational and emotional mechanisms to a bodily and affective state of well-being/the sensation of "meaningfulness" - and/or the "horrified fascination" of challenging specific power relations. That is, "enjoyment" is not necessarily tied to the individual subject as such, but is (also) ideologically structured: "to enjoy is not a matter of following one's spontaneous tendencies; it is rather something we do as a kind of [...] twisted ethical duty" (Žižek 2007, 79). In this context, the legitimacy of enjoyment (or suffering) form part of the ideological and structural (imperative) narrative which directs us to select and perform specific politically correct choices (in order to enjoy the promised "good life" or reach the dream of "happiness"), in other words: a structure of enjoyment which legitimates a political ideal while leaving aside others (cf. Žižek, 1997; Ahmed, 2010). Anonymous (political) lulz works, then, to put it in Ahmeds (2010) terms, as a "killjoy" in transgressing the (social/normative) principles of enjoyment. To enjoy "beyond the pleasure principle" is, hence, the "lulz."

${ }^{5}$ For a further discussion on the notion of enjoyment connected to ideological structures, see e.g., Žižek 2002 and Rone 2012; for the interrelation between rational (political) goals, passion and enjoyment, see as well the press release for "\#opSOTU," "For freedom [...] and of course, for the lulz." http://anonnews.org/press/item/2111/ (accessed August 30, 2013).

${ }^{6}$ Cf. Harding and Pribram (2004).
} 
itself. $^{7}$ This kind of "antagonism" or "radicalism" moves within such re-evaluations of democracy by symbolic actions of dissent through art, hacker culture or other forms of communication and social interaction in a permanent struggle for the control of meaning, signs and discourses (cf. Terdiman, 1989). Hence, "antagonism" (conflict) and hegemony (consensus) are both necessary since "this dimension [...] impedes the full totalization of society" (Mouffe, 2013, 1; also see, e.g. Laclau \& Mouffe, 1985). Mouffe argues: "We need to create democratic subjects who are passionate about democracy, who don't see democracy as a procedure that involves simply mediating among interest groups, but see it as a project, as something that is worth defending and fighting for. [...] I speak of the need for an "agonistic" public sphere - where dissent could be expressed - in this sphere real alternatives [to the current modes of democratic organisation] could be offered" (Mouffe in Zournazi, 2002, 146, 147; cf. Mouffe, 2005, 6, 24, 120).

The question is thus not about dissent as such, but about providing counter-discourses to the hegemonic discourses and this may, sometimes, be achieved through practices of civil disobedience, or, as Foucault suggests, put into operation by an "obligation" of the international citizenship to "speak out against every abuse of power, whoever its author, whoever its victims" (Foucault, [1981] 1994, 474). That is, the moral obligation to confront governments and the mechanisms of power and knowledge are not reduced to the institutional market of NGOs (neither to established media organisations), but it comprises also "the will of individuals" and the passion for an alternative social imaginary. In this emancipatory context, dissent, challenges to narratives and practices of power and knowledge, and counterhegemonic action may come from actors and movements "within" democracy who consider the modern state as an ethical, humanitarian and affective political project, not as a close, static, system defined rational and judicial rules. However, all this is "outside" the legal sphere, in other words, on its borders (cf. Mouffe, 2013; Foucault, 2007). With reference to the war in Bosnia/Herzegovina, Sontag writes: "It is the continuing coverage of the war in the absence of action to stop it that makes us mere spectators. Not television but our politicians have made history come to seem like re-runs. We get tired of watching the same show. If it seems unreal, it is because it's both so appalling and apparently so unstoppable" $(1994,105)$.

Evidentiary material concerning state corporate corruption, environmental catastrophes, or war crimes is being circulated by media outlets and continuously reproduced. Nevertheless, there is rarely any significant structural reaction or change in political life. According to Sontag, political inertia produces a distanced relationship to the mediated, catastrophic, world and not the repeated televised images per se. After all, why should we get involved in a story we already know from its beginning to its end? From this perspective, knowledge in itself (about specific misconducts, e.g.) is seldom enough to produce political change. It is not enough to record or leak evidence of social injustice, environmental data, and/or human suffering. However, we also need to put this evidentiary material in relation to hope and possibilities for action (cf. Chouliaraki, 2006), to the feelings that convince the public that there is a possibility of change through pressure on governments, specific actions, or by the development of a critical (un)conscious.

\section{Material and Vocabulary}

Our purpose when collecting and analysing the material for this paper was not to make a fully representative selection of Anonymous as such; but to pick up symptomatic examples, which illustrate the way in which counter-discourses can have social consequences. That is, we are

\footnotetext{
${ }^{7} \mathrm{~A}$ fantasmatic counter-discourse in the sense that Anonymous develop technological and aesthetic/affective strategies in order to transgress or challenge structural ideas and myths (ideological, unconscious, fantasies) of security, antagonism and freedom. That is, the cultural notion of specific apparatuses of security/control as necessary to protect ourselves from those "external threats" that are said to menace our Western political-economic lifestyle, "democratic values" and feeling of safety (in short, the vital ground over which the Western citizen can fully develop). Simultaneously, however, Anonymous constructs a phantasmagorical discourse through interpellations with the potential participant as someone that can make a "difference" by taking part of activist actions and by so become a "hero," reach "meaningfulness" and be set "free" - beyond (dominant) paradigms and ideological fantasies.
} 
concerned with the kind of (visual/symbolic) material that exemplifies the relationship between counter-hegemonic discourse and the potential for social change as well as with how hacking actions and/or the (digital) aesthetics of protest operate and may produce change (Lindgren, 2013).

The analysis has its focus in particular on those (communicative/hacking) actions of Anonymous that have generated a high degree of global media attention through which they have become the subject of public discussion. The degree of "media attention" has traditionally been assessed in the form of media coverage, documentary films, YouTube views, online forums, etc., but also by means of trending topics on Twitter, where the political actions of Anonymous were directly or indirectly referenced. As to Twitter, we also followed a large number of specific hashtags and we were engaged in dialogues with Anonymous associates and their posts/ongoing political discussions regarding questions of surveillance/censorship, military conflicts and human rights issues (tweets and distribution of links to articles, videos, images, and online conversations, etc.).

There are three key terms integrated in the activist vocabulary of Anonymous that require some explanation, IRC, DDoS attack and the "lulz":

(1) IRC (Internet Relay Chat) is an online communication platform. It is a "Real Time Internet Protocol for simultaneous text messaging or conferencing. It is designed primarily for group conversations in discussion forums and channel calls, but [it] also allows private messaging for one on one communications, and data transfers, including file exchanges" (Zato et al., 2012). Technically, these IRCs are public in the sense that they are open for anyone to be accessed. Nevertheless, they are regulated by specific Anonymous moderators. The IRCs provide a virtual space for Anonymous and others to communicate.

(2) DDoS attack refers to the method of "Distributed Denial of Service Attack." Here, an online "occupation tactic" is put in practice by Anonymous and other hacktivist groups with the aim to block Internet traffic. It works "via sending many malicious packets [simultaneously] which result in the failure of normal network services" (Zhong and Yue, 2010).

(3) The "lulz" is an expression used by Anonymous meaning "the laughs," as in doing something "for the lulz" ('for the laughs,' cf. Coleman, 2013b). The term is a variation of "lol" (Internet slang for 'laugh out loud') and can be considered in the context of personal or collective enjoyment or, as we shall elaborate below, as political "joy," "passion," or even "hope."

\section{Empirical Analysis}

In the following sections we will outline the history of Anonymous's political tactics by looking at their (hacking and aesthetic) actions as political practices with the purpose of framing and contextualising the movement beyond being simply about text or mere crimes of technology.

\subsection{Beginnings in the Project "Chanology"}

The first widely noted Anonymous operation was the "Project Chanology" which was directed against the Church of Scientology. Apparently without a definite and explicit political goal, Anonymous circulated online an internal propaganda video, starring the church's most fa-

\footnotetext{
${ }^{8}$ It should be emphasised that "lulz" is not necessarily "joy" in a traditional meaning. Encyclopedia Dramatica (a socially polemic, Wikipedia-alike, database, https://encyclopediadramatica.es/Lulz) writes about lulz as "a corruption of $L \mathrm{O} L[\ldots]$ signifying laughter at someone else's expense [...]. Lulz is engaged in by Internet users who have witnessed one major economic/environmental/political disaster too many and who thus view a state of voluntary, gleeful sociopathy over the world's current apocalyptic state [...] Definition: 1. the act of entertaining oneself with the misfortune of others; an agreeable occupation for the mind (LIKE SADISM BUT NOT). 2. somthing affording pleasure, diversion, or amusement, esp. a performance of some kind. 3. the essence which can be derived from an epic win." Translated politically, the lulz is a kind of Internet culture enjoyment and sarcasm that goes "outside the box," i.e., beyond the social/political imperative of what is enjoyable and what is not. It is, hence, not "enjoyable" from an assemble of formal authorities-perspective that someone hacks into statecorporate computer systems and leak classified information showing evidence of unconstitutional affairs, but it may very much be so from an activist point of view. The Anonymous hacktivists makes then use of the lulz as an affective political force, combining "political passion" with "the laughs."
} 
mous member Tom Cruise. ${ }^{9}$ This was apparently for the lulz in order to mock its overall content and eccentric character. The Church of Scientology responded by threatening specific online publishers with legal action (cf. Coleman, 2011) unless the film was withdrawn, and thus, the "war against the Church of Scientology" was started. Anonymous produced a video with a link embedded to the site http://forums.whyweprotest.net making use of strong visual and sound effects. ${ }^{10}$ A distorted voiceover simulating a computer voice, declared: "Hello, Scientology. We are Anonymous. Over the years, we have been watching you. Your campaigns of misinformation; suppression of dissent; your litigious nature [...] Anonymous has therefore decided that your organization should be destroyed. For the good of your followers, for the good of mankind - for the laughs - we shall expel you from the Internet and systematically dismantle the Church of Scientology in its present form. [...] Knowledge is free. [...] Expect us."

The video was successful - from a "PR" perspective - with over five million YouTube views at the time of writing. This video secured Anonymous a place on the internet map, but the way in which the video was produced - its feeling or aura - was even more important. With its time lapse effects and dramatic computer voiceover, the video "Message to Scientology" was rather performance-based than built upon traditional documentary aesthetics with a traditional rational or cognitive focus. As Anonymous activist Mike Vitale described the video, "If a computer told you it was going to beat the shit out of you, this is what it would look like" (Vitale in Knappenberger, 2012).

In this performance then, threats were expressed with a sense of humour - at least from an Anonymous perspective - and through intertextual aesthetics, making popular identification (and in extension, support) possible. In particular, the video formed and symbolically unified the previously fragmented layers of Anonymous. It gave rise to Anonymous as part of a field of struggle and/or as a larger movement of political activism, beyond, but not excluding humour and enjoyment. From this perspective, the Anonymous community media mobilised the lulz - here also understood as a political passion; engaging in resistance against the anti-democratic structure of the Church of Scientology - to communicate and create a new political environment, working on the fringes of the political and legal. ${ }^{11}$

If the first Anonymous video was of inspirational character, the second included rather practical information. It was a clear audiovisual handbook of street protests containing rules such as,

(\#1) "stay cool;" (\#8) "no violence;" (\#16) "know the dress code (forming a loose yet reasonable dress code for protest members will help to maintain cohesion and get the public to take you seriously);" (\#17) "cover your face (this will prevent your identification from videos taken by hostiles, other protesters or security);" (\#22) "document the demonstration (videos and pictures of the event may be used to corroborate your side of the story if law enforcement get involved; furthermore, posting images and videos of your heroic actions all over the internet is bound to generate win, exhorting other Anonymous to follow your glorious example)."12

Right from the beginning of the Anonymous history, there was, hence, an awareness of what aesthetics can do - or how political visual impact can be achieved, how to get media coverage. On this account, the "style warfare" of Anonymous - the Guy Fawkes masks and the black suits $(\# 16 ; 17)$ - works within the logic of mainstream media, which tends to seek out and publish spectacular pictures. ${ }^{13}$ In project Chanology, the strategic information put in circulation by Anonymous was supported by an audiovisual narrative in order to make the project understandable and to appeal to news media as well as to future Anonymous sympa-

\footnotetext{
${ }^{9}$ Tom Cruise Scientology Video, http://www.youtube.com/watch?v=UFBZ_uAbxS0 (accessed August 30, 2013).

${ }^{10}$ Message to Scientology: http://www.youtube.com/watch?v=JCbKv9yiLiQ) accessed August 30, 2013.

${ }^{11}$ Cf. Rodríguez, 2011, discussion on citizens' media as most powerful when understood as "performance" rather than a linear communication or information model.

${ }^{12}$ Code of Conduct, http://www.youtube.com/watch?v=-063clxiB8I (accessed August 30, 2013).

${ }^{13}$ The term "Style Warfare" is borrowed from Stuart Cosgrove (1984/2002).
} 
thisers. One of the most important (communicative) experiences of project Chanology was that "information" (alternative or not) must always, somehow, be narrated and contextualised (and affective) to become tangible (see, e.g., http://www.anonsweden.se/?page id=313, street protests, Anonymous wearing the Guy Fawkes mask. $)^{14}$

Anonymous's third video, "Call to Action" (2008), referred to the discourse of mainstream media: "Contrary to the assumptions of the media, Anonymous is not simply "a group of super hackers." Anonymous is a collective of individuals united by an awareness that someone must do the right thing [...]. We want you to know about all of these things that have been swept under the rug for far too long. The information is out there. It is yours for the taking. Arm yourself with knowledge". ${ }^{15}$

Two important aspects are interconnected here: first, a statement of the non-hierarchical variety of Anonymous outside the culture of hacking. Anonymous or the idea behind "free knowledge," that is, political, religious or corporate transparency, concerns all of us, no matter our individual features (cf. the unifying aesthetics). Second, the political struggle against Scientology must not necessarily be understood against the Church as such, but towards power structures that censor, conceal and/or try to prevent specific counter-information from spreading, even though this information might be of public interest. Politically (or ideologically) speaking, a parallel to the philosophy of WikiLeaks was hereby drawn and the war against Scientology was, in this sense, Anonymous's first "information war" against an established (institutional) power structure - with more of the same to follow.

\subsection{Momentum: The Arab Spring}

Many of the elements discussed above can also be found in "Operation Tunisia" (2011). Tunisian dictator Ben Ali had censored WikiLeaks cables and jailed a group of Tunisian journalists and bloggers. ${ }^{16}$ This, of course, provoked the hacktivist online crowd. However, the disturbing footage of street vendor Mohamed Bouazizi setting himself on fire to protest to the humiliation and harassment of the regime led to further and wider (re)actions.

Starting from this affective, human rights observation, in order to hinder state communication from circulating normally Anonymous organised DDoS attacks strategically directed towards major financial and government sites, and hacked into the Tunisian Prime Minister's website, replacing the existing front page with an image of a pirate ship and a message, stating: "Payback is a bitch, isn't it?" 17 Alongside these actions, Anonymous produced videos depicting the alternative realities of Tunisia, filmed by street citizens but edited by Anonymous, and audiovisual press releases, which were distributed via YouTube. However, the tactics, or the aesthetics, of resistance were not to end there. A "care package" with information and tools for being anonymous online to bypass Tunisian Internet state control was available for download. Information on how to block governmental online traffic (through DDoS) was also distributed online. In sum, by obstructing the online, governmental, communication flow and through this care package, Anonymous got directly involved in making communication in and outside the country difficult for the Tunisian government and easier for the Tunisian citizens.

In the case of "Operation Syria" (2011), Anonymous followed a similar strategy, by hacking the Syrian Ministry of Defence website and transforming it completely. Anonymous replaced the original structure of the site with the pre-Baathist era flag of Syria, including the logo of Anonymous in the centre, and provided links to the Syrian Revolution Facebook page, the Shaam News Network and other alternative media channels.

\footnotetext{
${ }^{14}$ Also see, https://secure.flickr.com/photos/anonymous9000/4281777022/, Anonymous protesting with the black suits and the Guy Fawkes masks. Picture from "Anonymous9000" (all data accessed August 30, 2013).

$15 \mathrm{http}: / /$ www.youtube.com/watch?v=YrkchXCzY70 (accessed August 30, 2013).

16 http://cpj.org/2011/01/as-ben-alis-regime-falls-3-tunisian-journalists-fr.php (accessed August 30, 2013). http://www.puppet99.com/?p=58; http://emajmagazine.com/2011/01/23/young-tunisian-i-cant-stop-smiling; http://www.dailykos.com/story/2011/01/20/937534/-Anonymous-plans-Op-Swift-Assist-in-Tunisia\# (accessed August 30, 2013).
} 


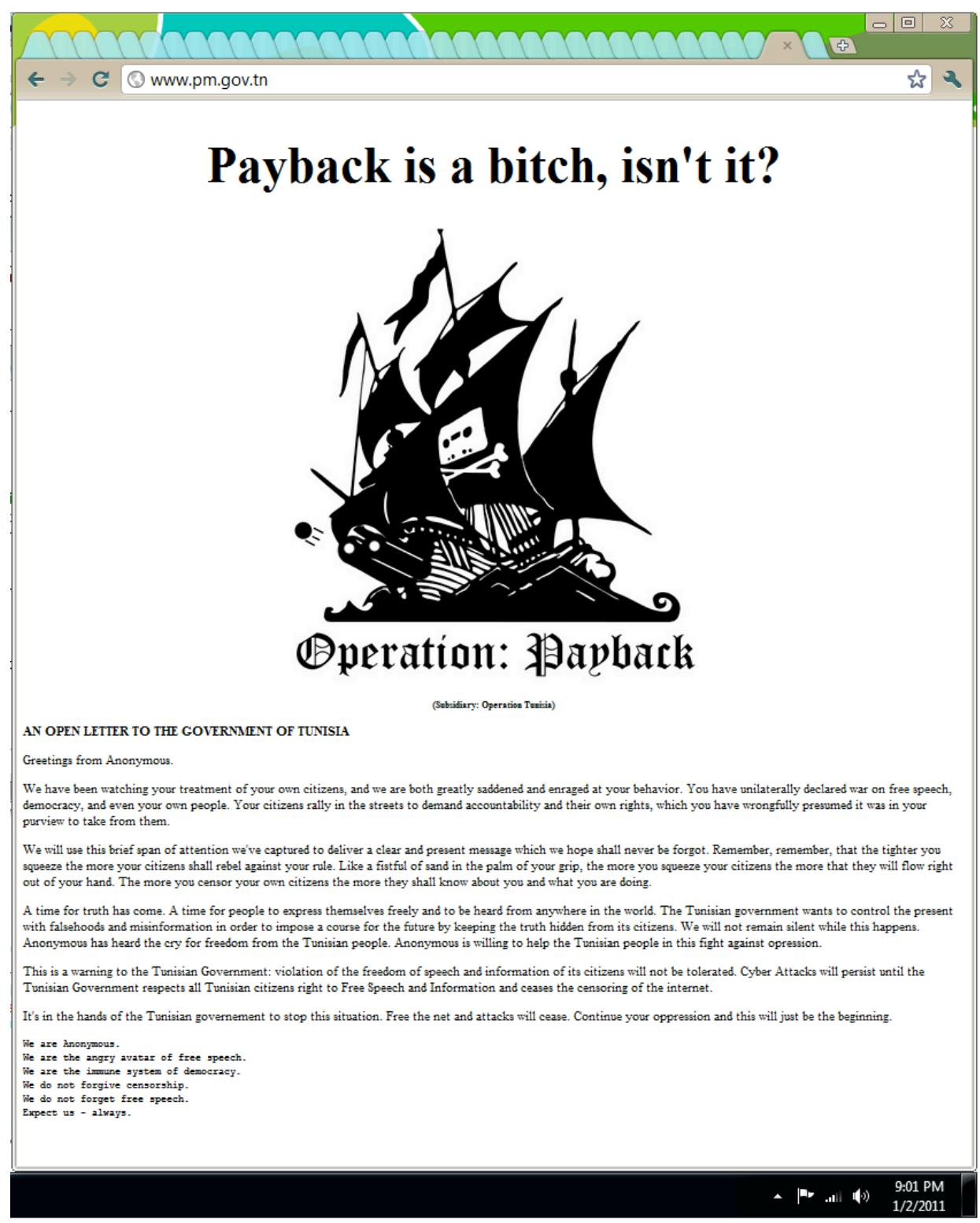

Figure 1: Screenshot of the 2011 hack: "Payback is a bitch, isn't it?" (Tunisian government web hacked by Anonymous) ${ }^{18}$.

Both of these acts of hacktivism inspired by the lulz garnered public attention and were seen as examples of symbolic civil counter-power, injecting, as we suggest, a sense of hope into the movement (an "optimistic narrative," in Chouliaraki's terms).

As a call to (participatory or direct) action, Anonymous also included a link to the IRC chat \#operationfreedom, providing digital activists with a place for meetings. In a way then, the mediated suffering of Bouazizi burning and the Anonymous hacking of the Syrian Ministry of Defence web - showing visible evidence of social injustice - connects to Chouliaraki's (2006) thoughts on the relationship between mediation and action. Defining this kind of mediation "emergency news," the author states that "shapes the spectators' conduct towards a cosmopolitan disposition to act; or where mediation manage to represent suffering in relation to [heterogeneous] contexts of activity - by connecting the concrete reality [in this context, the pictures of Bouazizi burning or other civilians suffering the abuse of power], together with a discourse on human rights and the question of why" (Chouliaraki,, 2006, 190-197).

18 http://emajmagazine.files.wordpress.com/2011/01/hack3.png (accessed 2011). 


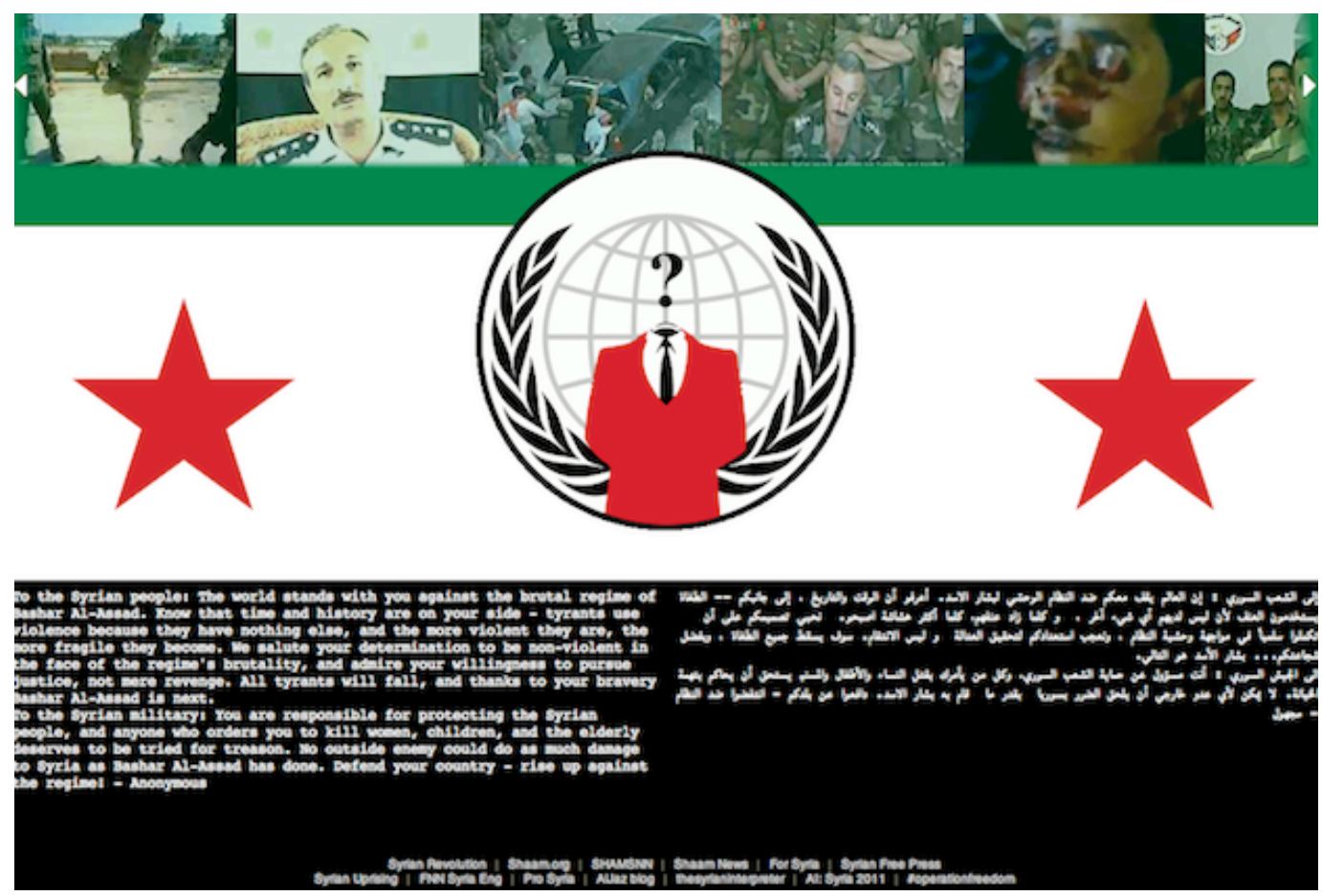

Figure 2: Syrian Ministry of Defence website, hacked by Anonymous (below) under a banner of photos of injured civilians and children $\left(\right.$ sreenshot $\left.^{19}\right)$.

According to this interpretation, Anonymous do not simply mediate suffering but also shape and embody concrete possibilities for response, demanding/inspiring public action - or, as Chouliaraki would have it, Anonymous "cultivate[s] new connectivities between spectators and distant sufferers" $(2006,196)$.

Obviously then, both the image of the pirate ship and the Anonymous version of the Syrian Ministry of Defence web had effects that went beyond mere semiotics. The very act of "hacking" into these governmental websites manifested that civil resistance groups and new social movements were a powerful political force to be reckoned with. That is, more than just a computer intrusion, the "hack" was a communicative act, saying (in relation to the Anonymous press releases) that no governmental power should have the right to repress or to censor economic/political information of public interest. It also suggested that Tunisian or Syrian disciplinary power could not equal modern "cyberwarfare" - the political discourses of power/knowledge triggered by Anonymous and their peers. ${ }^{20}$ Above all, the visual allegory of the hacks made a claim not only against censorship, but also for "freedom" as a way of life. That is, knowledge must be "free" - beyond political economic regulation; and we must be free to think and express ourselves differently. In this perspective, OpTunisia/Syria was, so far, Anonymous's most explicitly political involvement, symbolising "hacker culture" within a larger political context through a wide range of political (visual) strategies.

For example, the audiovisual press release of Operation Tunisia begins with a clear message: "Join us on the IRC" (text embedded in the description of the video). ${ }^{21}$ IRC is thus presented as a place where Anonymous (and others) can come together to meet and design specific operations. The press release video promotes such meetings and consequently, possibilities for action - and provides affective motives to participate/engage in political activism. The video is narrated in fragmented images (repetitive archive footage and graphics) of world disorder, struggle, and other associative visuals of revolutionary romanticism. All this is

${ }^{19}$ http://www.itp.net/585719-anonymous-hacks-syrian-government-website\#.Uick1M1r6wo (accessed August 30, 2013).

${ }^{20}$ See, e.g. Anonymous - \#Operation Syria, https://www.youtube.com/watch?v=olZzqa6nwos (accessed August $30,2013)$.

${ }^{21}$ https://www.youtube.com/watch?v=BFLaBRk9wY0 (accessed August 30, 2013). 
supported by calm background music (piano), and the characteristic computer voiceover, stating, "ANONYMOUS has heard the cries for freedom from the Tunisian people and has decided to help [...] The Tunisian attempts at censorship are doomed to failure if only we, ANONYMOUS, the people, take up our individual responsibilities. [...] Yes, this means YOU are ANONYMOUS. You will not forgive. You will not forget. You will not be denied your right to free speech, free press, free association and your right to an uncensored world of information provided to you through the Internet."

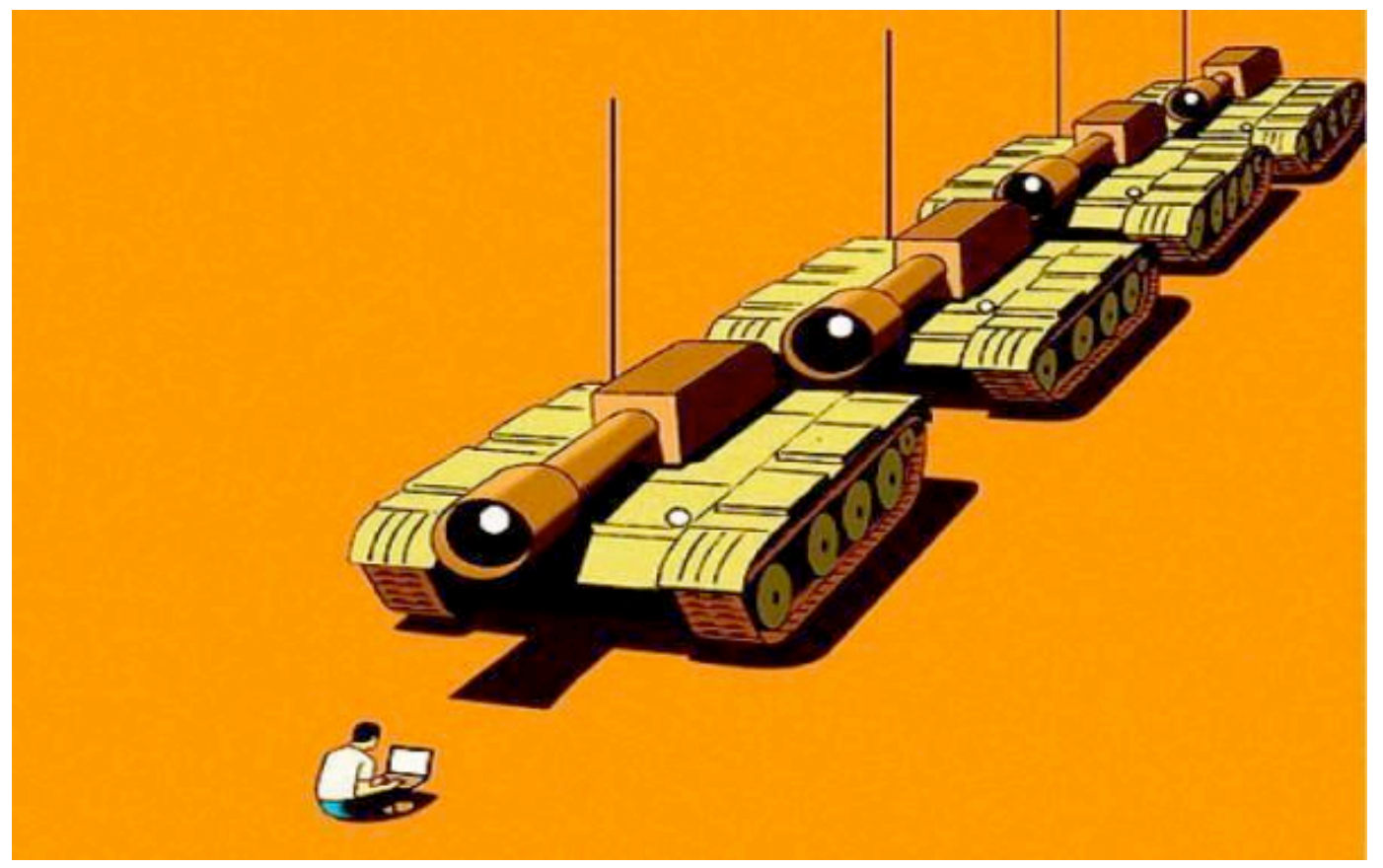

Figure 3: Anonymous reframe circulation of the iconic "tank man," originally from the Tiananmen Square protests in China (1989), here with a new title inspired by Martin Luther King, Jr (1963): "One has the moral responsibility to disobey unjust laws." (Illustration: Guy

$$
\text { Billout }{ }^{22} \text { ) }
$$

The voiceover rhetorically uses the notion of "freedom" aiming to emotionally "move" ("touch," or "push") the viewer into a specific direction of protests and actions. At first, these words may seem banal ("Anonymous has heard the cries for freedom; we the people; we [YOU] will not forgive; not forget; not tolerate the denial of our freedoms," etc.). However, they also raise fundamentally deeper questions regarding who should have the right to monitor the monitors and control the controllers. In a world of expanding state censorship and regulation of public information, where do we set the boundary between democracy and a police state? (In the long run, what are the subjective, intellectual and structural effects of fear; of a surveillance society? Who will benefit from this monitoring of civilian groups? Why is specific information not public?) What Anonymous does is thereby to mobilise affect (inspire a social/radical imaginary, and provide a detailed plan for public action) drawing on a body of discourses and counter-narratives, beyond the traditional frames established by state or commercial media. Considered in such a communicative-political perspective, the democratic contribution of Anonymous can be said to be less about "hacking" and more about raising or developing "critical thought" and/or provoking political debates (via its aesthetic and affective strategies).

22 https://twitter.com/AnonNewsSwe/status/351270113766420481/photo/1. Distributed by Twitter via Anonymous Sweden (@AnonNewsSwe), 30 June 2013 (12:24 PM), accessed August 30, 2013. 


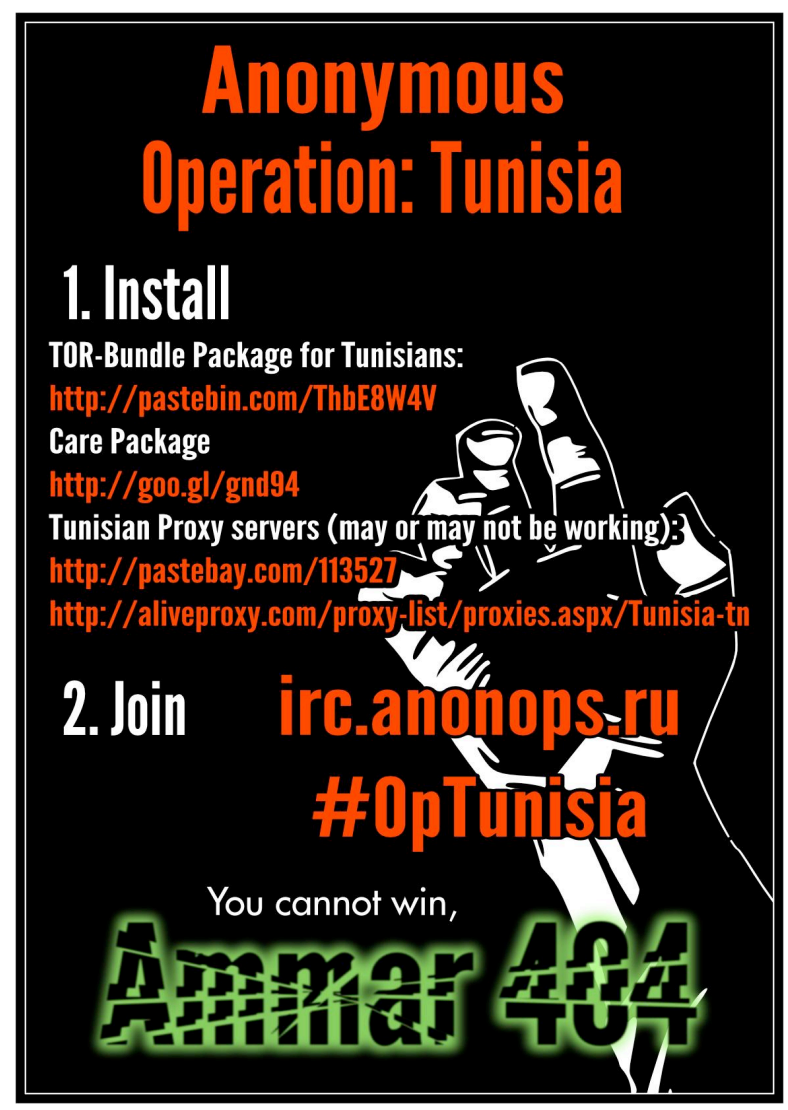

Figure 4: Graphic of "Operation Tunisia" containing detailed instructions on how to install the care package and join the IRC network on \#OpTunisia. ${ }^{23}$

The graphics above includes instructions on how to participate politically and it evokes a visual (affective) as well as a textual/cognitive experience. Embedded here is also a clearly defined two-step process on how to, substantially, engage in dissent "for a good cause." This kind of mix between aesthetics, affect, and usability that characterizes the rhetorical and political strategy of Anonymous. It is all about an accumulation of actions: an aesthetic communication of specific visual information, participation in street protests, distribution of flyers/propaganda posters/press releases and more concrete, technological assistance, such as the care package or the acts of hacking and leaking information, which makes up the political force of Anonymous.

With the YouTube video "Operation Tunisia - A message from Anonymous," Anonymous circulated previously unpublished footage of civil street protests in order to further causes to join the IRC network. The video begins with the text, "Warning: Some of the images that follow are very graphic and VERY disturbing. They are, however, the reality of Tunisia! Although most of these videos do not have source information, in a way, this makes them more credible." ${ }^{4}$ The computer voiceover continues by stating: "The (Tunisian) government has jailed the free bloggers and prevented local and international media from getting factual information out of the country. Anonymous is collecting videos and testimonies directly from Tunisian citizens on the streets and on the Internet. Because Anonymous thinks YOU NEED TO KNOW, Anonymous will fight against those who are trying to prevent you from knowing the truth. [...] Join the fight! ANONYMOUS needs more ideas! ANONYMOUS needs more fighters! Join the IRC!"

The video is symbolising Anonymous as an alternative communication channel where visual authenticity is enhanced - and an alternative truth is suggested - by the distribution of

\footnotetext{
${ }^{23} \mathrm{http}: / / \mathrm{www}$.anonamegame.net/forum/showthread.php?tid=25\&page=2 accessed January 2014.

24 http://www.youtube.com/watch?v=6opZoX3BTyl accessed August 30, 2013.
} 
grassroots visuals of street protests. However, it is neither Twitter or YouTube nor specific online graphics or the IRC network that make up Anonymous; it is the circulation, interaction and combination of these social media tools. That is, each of these tools works like a gateway to a wider affective and informational network and this is what makes social media as such powerful (potentially subversive or systematically propagandistic). This idea is also expressed by the Turkish Prime Minister Erdogan's description of Twitter as a troublemaker: "There is a trouble called Twitter. Unmitigated lies are there. [...] The thing called social media is a troublemaker in societies today [...]. To me, social media is the worst menace to society" (2013a, 2013b). ${ }^{25}$

Underlying such a statement is a view of social media as a potentially "disruptive" political force (Lindgren, 2013) since governmental power is unable to control the information flow and to prevent alternative media from creating public opinion or inspiring to collective direct action. $^{26}$ This is not to say that international mainstream media does not cover geopolitical questions of conflict, rather that the aesthetics of Anonymous works, as Knappenberger (2012b) puts it, as a unifying "loudspeaker" for (otherwise) single, anonymous, voices and are, hence, an alternative to other, large, traditional media organisations. The Anonymous aesthetics then, both unites and makes individual actions appear as one, where the use of the Guy Fawkes mask, the distorted computer voiceover in the YouTube videos, and/or the Anonymous logo, etc., give a sense of unity, a sense of magnitude. By that comparison, Anonymous looks like a powerful movement with the capacity to inspire political actions of dissent, leak classified information and provide alternatives to the narratives framed by the ruling political economy.

In essence, underlying utterances like the above visuals is a perspective from political economy focusing on state-corporate alliances and power practices connected to questions of ownership, control, production, distribution and consumption. According to this view, the domestic as well as international mainstream media have failed to report on Turkish protests or other global actions independently of political/financial interests, and thereby repress further dialogues and potential debates. This was the core issue for "OpSyria" wherein Anonymous - besides the production of the Syrian Care Package - created "emergency independent media centers [...] [to] keep open the lines of telecommunication." 27 The audiovisual press release of "Operation Egypt" (2011) followed a similar pattern: "To the Egyptian Government [...] not only will we attack your government websites, Anonymous will also make sure that the international media sees the horrid reality you impose upon your people. [...] Join us on the IRC - irc.anonops.ru \#opEgypt! [while documentary footage of civil protests and police brutality is seen]." 28

What Anonymous is communicating is thus visible and emotional "evidence" of institutional disciplinary power abuse - a good reason for action. The message is: download the Anonymous Care Package, put on the Guy Fawkes mask and/or stay tuned for specific Twitter hashtags, for updates and instructions. However, if, according to Western mainstream media, Anonymous's active participation and political consciousness in the Arab Spring movements, through the hack of strategic websites or technological assistance for human rights issues was somewhat associated with "the (oppressed) people's uprising," the political connotations of Anonymous began to change in "OpAntiSec." ${ }^{29}$

\footnotetext{
${ }^{25}$ See http://www.hurriyetdailynews.com/twitter-is-a-troublemaker-turkish-pm.aspx?pagelD=238\&nID=48084\&NewsCatID=338; http://www.guardian.co.uk/world/2013/jun/02/turkishprotesters-control-istanbul-square?CMP=twt_gu (accessed August 30, 2013).

${ }^{26}$ I.e., an alternative to domestic mainstream media. An example of such visual counter-narrative provided by citizen's media can be seen in the Turkey riots (2013) (see below).

${ }^{27}$ Anonymous - \#Operation Syria, http://youtu.be/olZzqa6nwos (accessed August 30, 2013). This kind of Care Package was also distributed in the Syria conflict of August, 2013, see, e.g. Anonymous \#opSyria Silence is a War Crime, https://www.youtube.com/watch?v=uqw2McsayWI (accessed August 30, 2013).

$28 \mathrm{http}: / /$ www.youtube.com/watch?v=yOLc3B2V4AM (accessed August 30, 2013).

29 See, for example, the Anonymous actions to "democracy issues" in relation to the Arab Spring protests, http://www.huffingtonpost.com/2011/01/29/anonymous-internet-egypt n 815889.html; http://www.nytimes.com/2011/02/03/world/middleeast/03hackers.html?_r=0;
} 


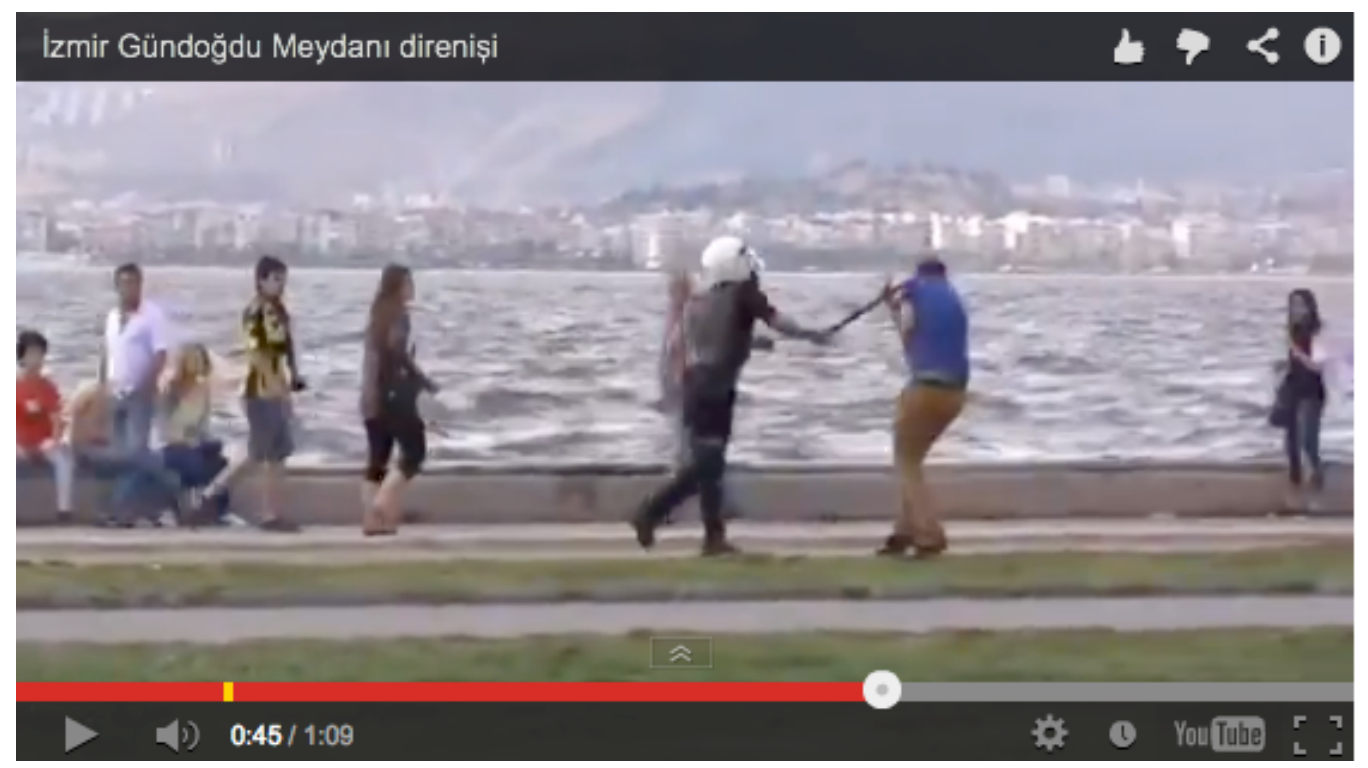

Figure 5: Screenshot of the Turkey riots. Visual evidence of police brutality, distributed by Anonymous and other social movement groups via Twitter and YouTube, and elsewhere. ${ }^{30}$

\subsection{Against Surveillance}

In "Operation AntiSec" (anti security), a combination of Anonymous and LulzSec (a hacker collective associated to Anonymous) hacking actions attacked a wide range of (inter)national/governmental websites and pro-censorship groups. Their claim was that it is "time to show the corrupt governments of the world that they have no right to censor what they do not own [...]. We invite you to join us in our fight against censorship and corrupt governments" (Message from Anonymous: Operation AntiSec 2011) ${ }^{31}$ OpAntiSec entailed a switch of geopolitical direction and, as a consequence, Anonymous became increasingly seen as a threat to Western "democracy." This was mainly because institutions like Booz Allen Hamilton, NATO and the "global intelligence firm" Stratfor were hacked. ${ }^{32}$ According to Anonymous associate Barrett Brown, these targets were selected for being large American state-corporate (military) alliances that were "against the free information movement" (2011). ${ }^{33}$

Brown claimed that the hacks formed part of an investigation by Anonymous with the aim of finding out why these power structures had positioned themselves against state or corporate (information) transparency. In our view, Anonymous posed questions such as: Why are specific state or corporate data labelled as "sensitive" beyond public/institutional discourse? Why should they only be revealed by agents within the power structure after having been mediated and "washed" through several phases of political consent? Who gains from preventing data of "public interest" to go public? These are the key questions that Anonymous want to debate when revealing "sensitive data."

http://www.nbcnews.com/id/41407082/ns/technology and science-security/t/hacktivists-launch-second-attackegypt/\#.UejrS81r6wo (accessed August 30, 2013).

30 See YouTube video "02.06.2013 İzmir Gündoğdu Meydanı polis müdahale" (Turkey Riots, 2013), http://www.youtube.com/watch?v=XThjR-7F0io (accessed August 30, 2013). See, also, the tweet regarding the Turkey riots (2013). "Revolution will not be televised, it will be tweeted," i.e. communicated beyond the domestic media frame; shared via Anonymous Operations (@Anon_Central), 03 June 2013 (08:07 PM), (accessed August 30, 2013), https://twitter.com/AnonInsiders/status/341647460076228608

31 http://www.youtube.com/watch?v=IHApqy3n3Fs (accessed August 30, 2013)

32 DDoS targeting U.S. financial markets took place in OpPayBack (2010-2011) but it was not until OpAntiSec (2011) that Anonymous (and LulzSec, together with the FBI-informant Sabu as a co-actor) in a more systematic order started to hack and leak American state-corporate alliances.

${ }^{33}$ Anonymous details Stratfor Christmas hack, http://rt.com/usa/anonymous-stratfor-barrett-firm-777/ (accessed August 30, 2013). 
Among these hacks, the private U.S. security and intelligence firm Stratfor (Strategic Forecasting Inc.) was to become especially significant. On Christmas Eve, 2011, Anonymous and LulzSec hacked into the servers of Stratfor and leaked about five million private emails to WikiLeaks ("The Global Intelligence Files"). Based on the WikiLeaks release, media outlets such as The Guardian and Rolling Stone Magazine started to report on how Stratfor secretly collaborated with the U.S. Department of Homeland Security with the aim to develop strategies for civilian domestic surveillance. ${ }^{34}$ The Stratfor hack thus illustrated the power and capacity of hacker culture. Together with LulzSec, Anonymous stole "60,000 credit card numbers, along with records for 860,000 clients of Stratfor, staff e-mails and financial data ... The FBI later confirmed that the credit cards had been used to make at least $\$ 700,000$ [to charity]" (Olson, 2012).

However, the hack also manifested something else. In general, the Anonymous hacking actions of political and financial sites can be seen as symbolic operations: Anonymous, or the effects of its actions bring about a need for debating the relationship between knowledge and power. Anonymous argued that specific state-corporate information needs to be free (transparent) and not solely regulated and organised by institutional power. Constructed in this way, (political) cyber piracy can be read as an attempt to investigate what is going on behind the façade of democracy; an attempt to move closer to the "truth" and make it public. From this political perspective, Anonymous activities constitute something more than mere computer intrusion. What Anonymous shows, more than the actual "hack" or the information gained through hacking, is that no server can hide information securely. This has a strong symbolic meaning. No civilian group can ever match the institutional power-infrastructure when it comes to traditional war technologies. However, in cyber- or information wars those terms change, at least theoretically. From this perspective, the activities by Anonymous can be construed as symbolic acts of political counter-power, and this is where the potential of hacker-culture as a political movement comes into play. As Anonymous says, in their characteristic YouTube video, "Anonymous Operation Last Resort" (2013): ${ }^{35}$

We have seen how the law is wielded less and less to uphold justice, and more and more to exercise control, authority and power in the interests of oppression or personal gain. [...] Two weeks ago today, a line was crossed. Two weeks ago today, Aaron Swartz ${ }^{36}$ was killed. Killed because he faced an impossible choice [...] the very real threat of highly disproportionate sentencing. [...] There must be a return to proportionality of punishment with respect to actual harm caused, and consideration of motive and men's reason. [...] Laws must be upheld unselectively, and not used as a weapon of government to make examples of those it deems threatening to its power. This time there will be change, or there will be chaos. [The YouTube video provides links to warheads.] ${ }^{37}$

${ }^{34}$ See, e.g., WikiLeaks's Stratfor dump lifts lid on intelligence-industrial complex (The Guardian, February 28, 2012), http://www.guardian.co.uk/commentisfree/cifamerica/2012/feb/28/wikileaks-intelligence-industrialcomplex; Exclusive: Homeland Security Kept Tabs on Occupy Wall Street (Rolling Stone, February 28, 2012), http://www.rollingstone.com/politics/blogs/national-affairs/exclusive-homeland-security-kept-tabs-on-occupywall-street-20120228. Also see, Jeremy Hammond Pleads Guilty to Stratfor Leak, Faces Harsh Sentence for Online Protest: Press Release \& Jeremy's Statement (Sparrow Media, May 28, 2013),

http://www.sparrowmedia.net/2013/05/jeremy-hammond-plea-deal/ (all data accessed August 30, 2013).

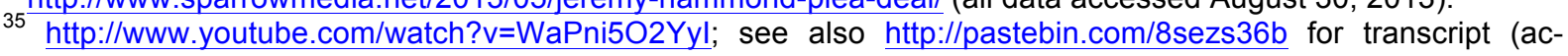
cessed August 30, 2013).

${ }^{36}$ Swartz was a freedom-of-information advocate, activist and hacker who committed suicide after facing up to 50 years in prison and a $\$ 1$ million fine for downloading and distributing a large number of academic journal articles from the JSTOR repository.

${ }^{37}$ According to an article published at the technology news site by John Leyden, on January 28, 2013, The Register, Anonymous "is also threatening to expose sensitive information about the US government, purportedly contained in a 1.3GB encrypted file titled Warhead-US-DOJ-LEA-2013.AES256, which it claimed it had obtained after infiltrating numerous unnamed sites. The group has encouraged internet denizens to distribute the file (which it refers to as a "warhead"), and it has since become available as a torrent through file-sharing networks." See http://www.theregister.co.uk/2013/01/28/anon_doj_hack_swartz_protest/ (accessed August 30, 2013). 


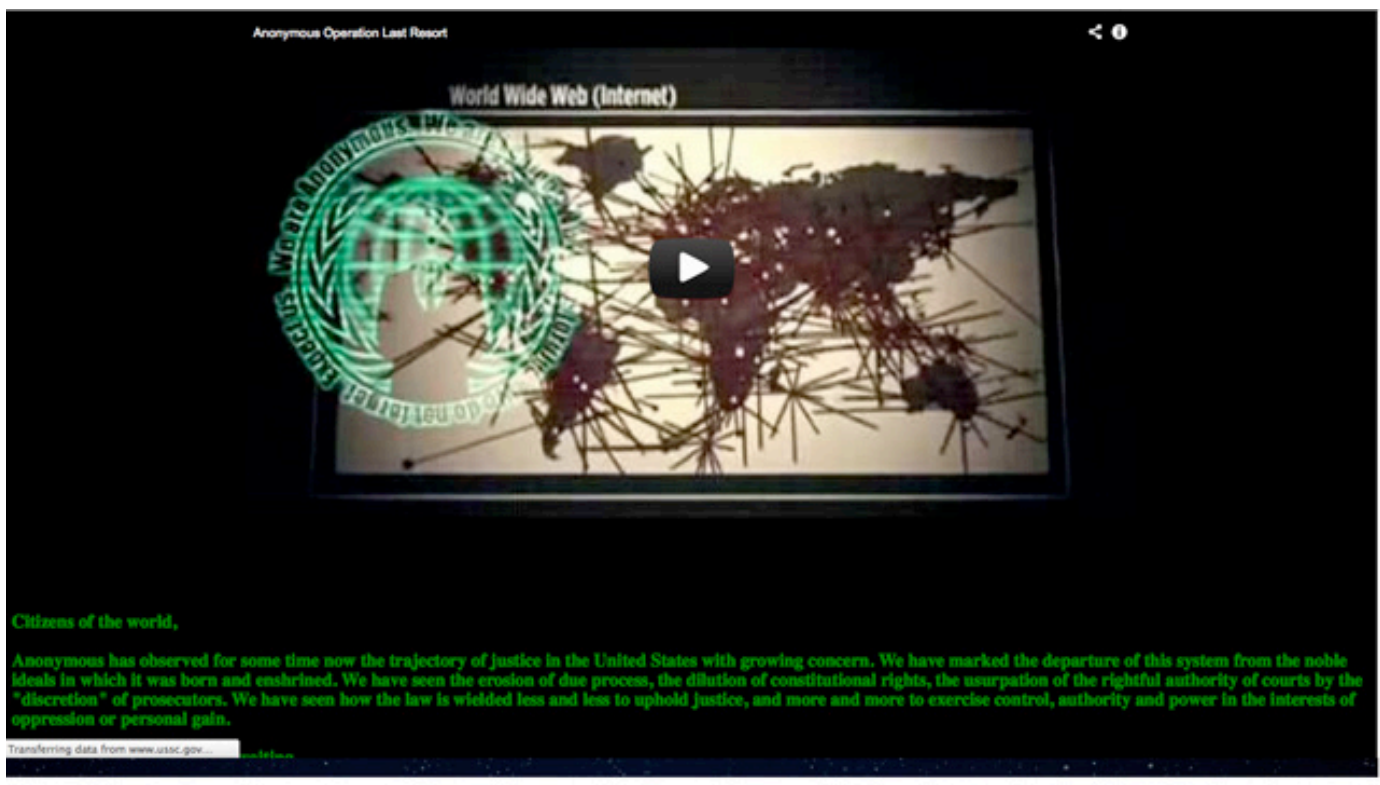

Figure 6: Screenshot of the hacked website of the United States Sentencing Commission, including the Anonymous YouTube video "Operation Last Resort" (first hack). ${ }^{38}$

With such messages, Anonymous argues that it is not reasonable to have a judicial system with "disproportionate" penalties for downloading copyrighted material, meant to be accessed publicly (as in the case of Aaron Swartz). Revealing strategies about state-corporate spying (Stratfor) or for leaking visual information showing war crimes (cf. the case of Manning and the "collateral murder" YouTube video published by WikiLeaks in 2010) should not be criminalized, while state (war or spying) "crimes" go unpunished. ${ }^{39}$ According to Anonymous, the only way of discussing these issues is to reveal sensitive data, spread them with the help of the Anonymous narrative and aesthetics of protest and force the debate via a popular form.

As the video game aesthetics of Asteroids indicates, the new digital aesthetics of protest of Anonymous works very much on a level of abstraction. That is, beyond the visual sign. The aesthetics of Asteroids points to Anonymous as a source of political lulz, an affective source of political enjoyment (cf. Anonymous video "LulzXmas," also posted on the hacked Stratfor website, ending with Charlie Chaplin's discourse on freedom from The Great Dictator, 1940). ${ }^{40}$ Anonymous-associative Jeremy Hammond frames this sentiment in an explicit way when he observe in an interview that "boredom is counterrevolutionary. Political resistance needs to be fun, or no one will want to participate. ${ }^{" 41}$ Challenging political and economic power by posting a video of Chaplin - or by transforming the web of the United States Sentencing Commission into a game of Asteroids in a clear dialogue with popular culture; easy to relate and identify with - is, hence, quite fun (and a sign of "courage"). ${ }^{42}$ Fun, as Hammond notes, works inspiring (cf. Spinoza on primary affects, in this case the intensiveness of joy -

38 Source: http://gawker.com/5979203/anonymous-hacks-department-of-justice-website-threatens-to-launchmultiple-warheads accessed August 30, 2013.

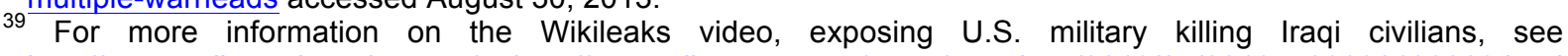
http://www.collateralmurder.com/; http://www.aljazeera.com/news/americas/2010/04/20104520036138869.html (accessed August 30, 2013).

${ }^{40} \mathrm{http}: / /$ nwlinux.com/anonymous-delivers-christmas-eve-hack-to-stratfor/ ;

http://www.youtube.com/watch?v=BdqoSWtYpHE ; also see stratfor.com - xmas defacement, http://www.youtube.com/watch?v=ZLPC vdcZcQ (accessed August 30, 2013).

The YouTube video, For the Oakland Commune, showing street protests in Oakland November 2, 2011, were also posted on the Stratfor website after Anonymous hack, http://www.youtube.com/watch?v=7Ev8Bg4nT6w (accessed August 30, 2013).

${ }^{41}$ Our translation, see, http://www.rollingstone.com/culture/news/the-rise-and-fall-of-jeremy-hammond-enemy-ofthe-state-20121207?page=2 (accessed August 30, 2013).

42 Or, as Wikileaks Sarah Harrison (2013) puts it: "courage is contagious." See, http://wikileaks.org/Statement-bySarah-Harrison-on.html (accessed December 12, 2013). 
or the lulz - as the capacity to affect and expand power; the power of action). ${ }^{43}$ Put differently, "passion" or "joy" as an effective and necessary political component (a "drive") with a concrete potential for mobilising resistance towards the radical imaginary.

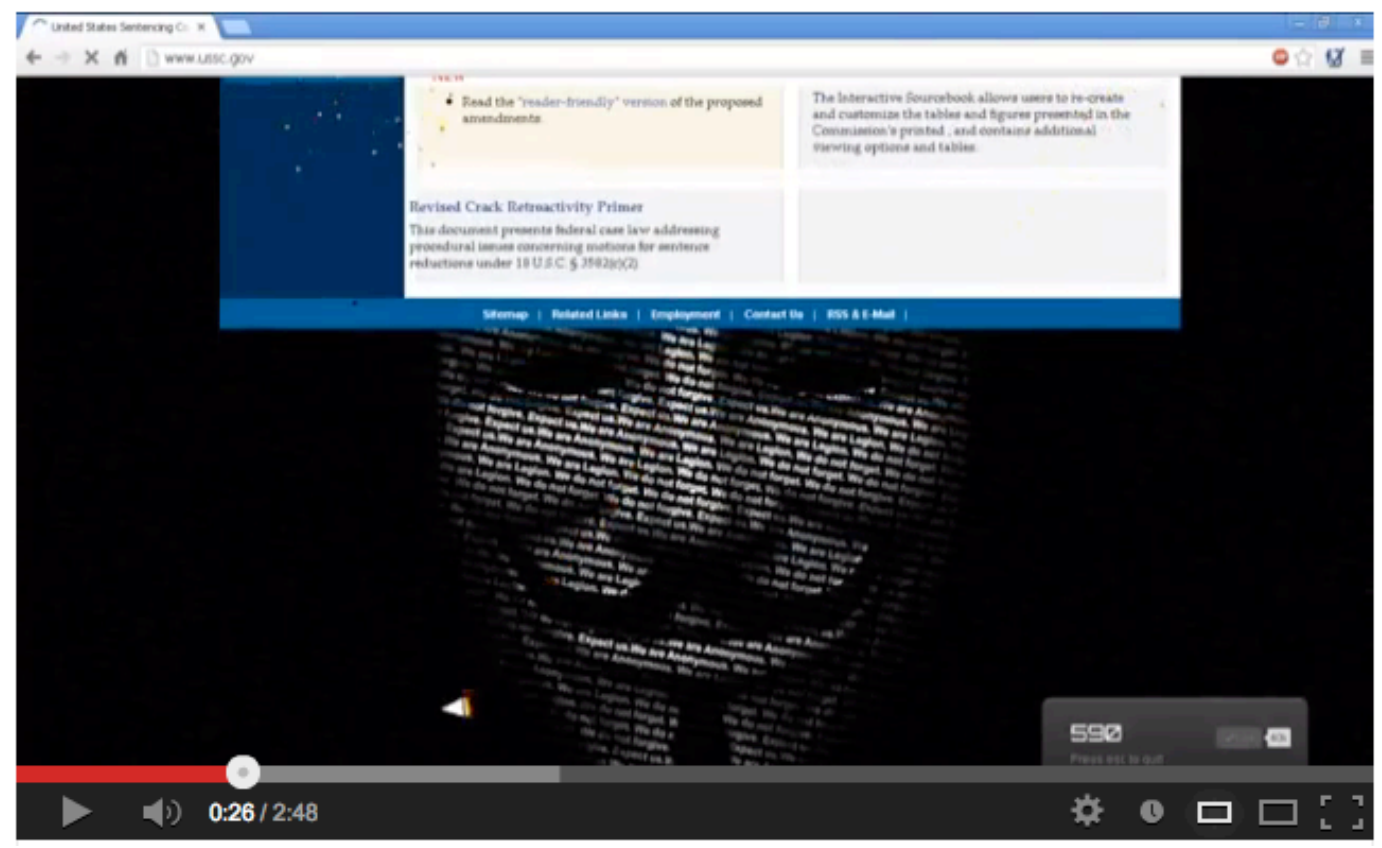

Figure 7: The website after Anonymous (second) hack, transformed into the video game Asteroids (here via YouTube). ${ }^{44}$

However, at this time of writing, the full story of the whistleblowing warheads has not yet been made public. A group of Anonymous members has stated that Anonymous de facto was not directly responsible for OpLastResort. ${ }^{45}$ However, about six months after the hack of the United States Sentencing Commission site and only days after Anonymous activist Jeremy Hammond pleaded guilty to the Stratfor hack (facing 10 years in prison) and the Bradley Manning trial (facing lifetime or worse), a former CIA and NSA employee, Edward Snowden, leaked classified information regarding strategies of the NSA Prism program. That is, secret information on how the U.S. government mass surveillance program "legally" taps millions of civilians in and outside the U.S. by collecting metadata on private phone conversations, detailed information on personal purchases made with credit cards, or material exposing the content of Skype calls and emails. Snowden also revealed that Internet conglomerates such as Google, Facebook, Yahoo and Apple have been secretly collaborating with the U.S. government for years by giving direct access to private information.

These leaks (Snowden's revelations together with the Stratfor-leak etc.), thus allows us a glimpse into a world of state-corporate spying on civilians; a surveillance society taking place in order, according to U.S. President Obama, to "prevent terrorism." ${ }^{46}$ This entails a shift in the symbolic politics of (counter)terrorism, according to which not only "the others" but also Western citizens are understood as "potential threats."

It does not really matter here if neither the NSA leak nor OpLastResort explicitly had anything to do with Anonymous. What matters is the accumulation of leaks in close relation to each other and how they potentially affect public opinion, the public image of democracy and our self-image as citizens - or, rather, as potential threats. The objective behind these hacks

${ }^{43}$ For a further discussion on Spinoza and the relationship between politics, affect and imagination, see, e.g., Williams 2007. Also see Deleuze, 1988.

${ }^{44} \mathrm{http}: / /$ www.youtube.com/watch?v=dvNKs2ND3fA accessed August 30, 2013.

45 http://www.dailydot.com/news/anonymous-operation-last-resort-hoax/ (accessed August 30, 2013).

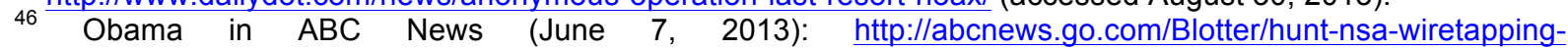
leaker/story?id=19348771 (accessed August 30, 2013). 
and leaks - considered as acts of counter-discourse - is hence to make them public and make political opinion internationally aware of how power and democracy operates.

\subsection{Occupy}

We will begin this section by contextualising the overlapping relation between (Anonymous) online and offline strategies where the online aesthetics of the Occupy movement is looked at in regard to how images may influence and play significant roles in the "offline world." In the OpTunisia care package, Anonymous stated: "This is *your* revolution. It will neither be Twittered nor televised or IRC'ed. You *must* hit the streets or you *will* lose the fight. Always stay safe, once you get arrested you cannot do anything for yourself or your people. Your government *is* watching you." ${ }^{*} 7$

The thrust of this message is that "online" media outlets and platforms are important. They need to circulate information and communicate strategies of mobilisation over geopolitical boundaries, but always in relation to other "offline" actions. After all, approximately 70 percent of the world's population has no access to the Internet, and socio-cultural/political factors such as education and class cannot simply be neglected in terms of the way in which specific digital activist actions are executed (cf. Bourdieu's concept of the accumulation of symbolic resources, 1986). ${ }^{48}$

Hence, it goes without saying that political activism cannot only depend on "online" actions (cf. also Reed, 2013) or the inherent technological features of social media. However, onand offline activities may also, more or less successfully, intersect. Examples are the Arab Spring hacktivist operations and strategies of circumventing surveillance as well as in Anonymous's participation in street level social movements such as Occupy Wall Street. Let us consider first some brief notes on the Occupy Wall Street (OWS) movement before returning to the visual on- and offline tactics of Anonymous. According to http://www.occupywallst.org/, OWS "is a leaderless resistance movement with people of many colours, genders and political persuasions. The one thing we all have in common is that We Are The $99 \%$ that will no longer tolerate the greed and corruption of the $1 \%$. We are using the revolutionary Arab Spring tactic to achieve our ends and encourage the use of nonviolence to maximize the safety of all participants." 49

The "Arab Spring tactic" is here the one of using the public (physical and virtual) sphere as a stage and forum for exposing exclusions, misconducts and other effects of normative power - and demand social change, where acquiring media coverage becomes crucial in order to receive public and political support. The political slogan "We Are The 99\%" refers to the effects of economic concentration and inequality - the social consequences of the fact that $40 \%$ of the world's wealth is in the hands of $1 \%$ of the population. ${ }^{50}$ Put another way, as globalisation expands, political and economic power tends to become increasingly centralized. According to this logic, the neoliberal version of democracy will not be able to balance out economic and political inequalities since none of the beneficiaries of the current power structure (the elite) will struggle for the majority of the global population. The idea behind OWS is then to take routine practices of political and financial power and drag them into the public eye by peacefully occupying public spaces locally or globally - and thereby to occupy an (inter)national political conscience (cf. Chomsky, 2012).

According to a tweet written by Anonymous associative @OpManning, "Anonymous has done things both magnificent \& utterly base. But without real people acting on it, freeing information is futile." ${ }^{51}$ Hence, in referring to the importance of "offline tactics," if the people's

\footnotetext{
${ }^{47}$ http://pastebin.com/ejAEMQxQ (accessed August 30, 2013).

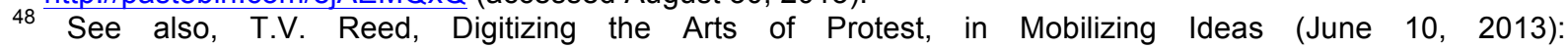
http://mobilizingideas.wordpress.com/2013/06/10/digitizing-the-arts-of-protest/ and/or the report "ICT data for the world, by geographic regions and by level of development" (excel): http://www.itu.int/en/ITUD/Statistics/Pages/stat/default.aspx (accessed August 30, 2013).

49 http://occupywallst.org (accessed August 30, 2013).

50 See "The Shocking Amount of Wealth and Power Held by $0.001 \%$ of the World Population", http://www.alternet.org/economy/global-power-elite-exposed (accessed August 30, 2013).

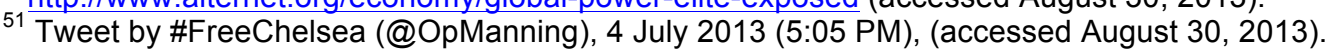


uprising against economic and political concentration (and corruption) is to come about, there must be people in the streets "pushing" the subject and applying pressure. This, then, is (also) where the revolutionary aesthetics of Anonymous works as an inspiring factor. In their YouTube video "Hello Wall Street - We Are Anonymous" the movement is not specifically encouraging hacktivism, but rather mass street protests by showing footage of police brutality in slow motion, documentary footage of military attacks and a group of Anonymous supporters protesting peacefully. Hence, the visual clash between institutional violence protecting the state-corporate alliance and the civil non-violent street protest is made into a key affective narrative, suggesting the abuse of power. The clip was uploaded on August 23 (2011), almost a month before the actual, offline, protests of OWS. This early YouTube video was then, we could assume, aimed to gain attention and create an affective perception of injustice. $^{52}$

As the OWS protests took place and developed there was, according to Anonymous, a need for further calls to action. On September 28, Anonymous released a YouTube video showing documentary footage of the OWS protests including a message on the importance of an alternative to the mainstream media in the form of blogging, leaking and sharing (audiovisual and textual) files on a cluster of social media platforms, thereby evoking "truths" and actions otherwise invisible on mainstream news channels. ${ }^{53}$ In other words, an alternative to the political-economic structure: [Anonymous voiceover] "Occupy protests continue to grow despite the puppet media, who is bought and controlled by politicians and corporations [...] Fight greed, corruption and corporate control of our democracy. [...] We will not stand for your atrocities and injustices any longer. We are Bradley Manning, we are Scott Olsen. [...] We are people. We are free. We are one. We are Anonymous."

In the voiceover as in the video itself, the framing of "we, the governed, the people" (oppressed) against the governmental body of state-authority, and its disciplinary techniques of governing, connects to significant consequences of dysfunctional security systems. Among other images, a marine is seen holding up a picture of the Iraqi war veteran Scott Olsen, critically injured by Oakland police during the Occupy protests. The visual narrative of the video tells us that Oakland is under attack, but not from "external terrorist threats," but rather from the one's (U.S. domestic police) that are supposed to be protecting "us, the people." That is, a narrative saying: "the police doesn't protect the us, the people; the police protect state/economic-power (the elite; the 1\%), just look at the image evidence that mainstream media censor. Rise up, react, occupy." In particular, the pictures of the seriously injured Iraqi war veteran Scott Olsen as a result of domestic police action have analogies with the Tunisian police battery of Bouazizi (and of course, the picture of Bouazizi in flames, 2011) and/or the Turkish "woman in red" who got sprayed with teargas by Turkish police and became a symbolic representation and icon of the Turkey protests (2013). All these (alternative, noncensored) pictures serve as individual symbols - strong, affective, visible evidence - of institutional power abuse - an excessive use of police force, systematic strategies of media censorship, etc. - and in catalyzing the potential "turning point" or wider public reaction to such institutional violence and power abuse (cf. W.J.T. Mitchell's term "contagion" employed in his iconological approach to describe the images that go "viral in the global media" [2013, x, 96]). ${ }^{55}$ As Mitchell notes, such "viral images" cannot be the "cause" of revolutions but can

${ }^{52}$ Hello Wall Street - We Are Anonymous, http://www.youtube.com/watch?v=T-eFxCDx7Yw (accessed August 30, 2013).

${ }^{53}$ Anonymous Occupy Wall Street Call to Action, http://www.youtube.com/watch?v=8IrGZnKf888 (accessed Au${ }_{54}$ gust 30, 2013).

54 Anonymous - Message to Occupy the World 11-18-11, http://www.youtube.com/watch?v=VqWdyM91hFA (accessed August 30, 2013).

55 See, for instance, the icon of the Turkey riots (2013), the "woman in red," as an example of such "contagious," affective, and inspiring political aesthetics of protests and its various reframes within the public sphere, where they are circulating between art, Anonymous and social or traditional (mass) media: http://worldnews.nbcnews.com/_news/2013/06/04/18741084-woman-in-red-sprayed-with-teargas-becomessymbol-of-turkey-protestshttp://pbs.twimg.com/media/BL8Im7hCEAAio39.jpg http://www.anonsource.org/p/sgallery/gallery.php?uview.101.1; 369jA/UbQV3xUuKcl/AAAAAAAABml/2_FCWZgZYeU/s1600/woman+in+red+dress.jpg. 
"serve as catalysts to set off a chain reaction of mass emotion" (ibid., 96), and this production and distribution of a visual counter-narrative, showing censored images of domestic police brutality in different forms, is one of the objectives behind Anonymous Occupy aesthetics in order to "occupy" public political consciousness. A consciousness not isolated to stateauthority in relation to protests, but connected to surrounding contexts and the reason behind the protests: economic inequality, failures in the liberal-economic democratic system and dysfunctional practices of state-corporate techniques of "security."

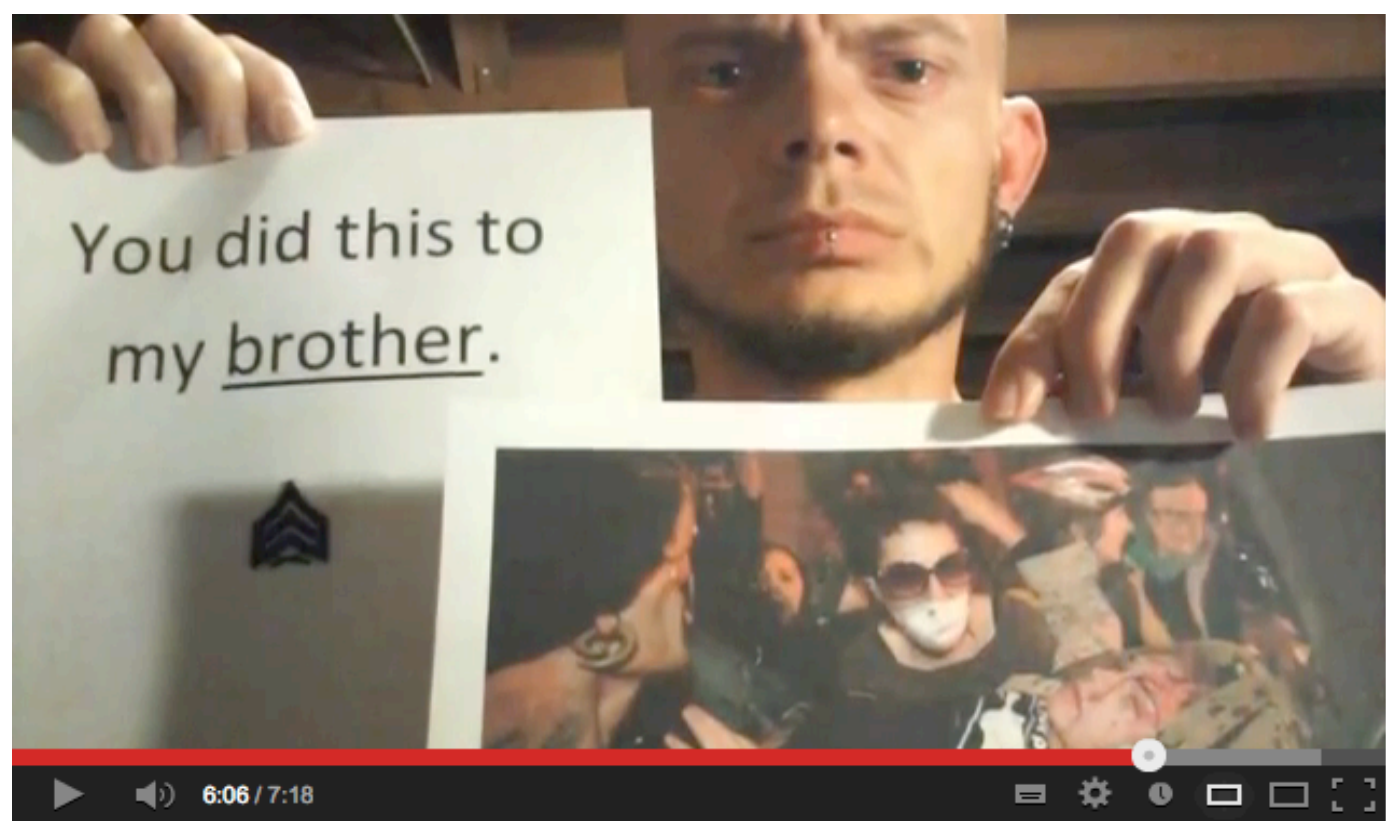

Figure 8: Institutional violence at Occupy Oakland (2011). Marine holding up picture of Iraqi war veteran Scott Olsen, injured by Oakland police during the Occupy protests. Frame from the YouTube video "Anonymous - Message to Occupy the World 11-18-11."

By all accounts then, when the digital protests aesthetics of Anonymous are narrated through specific online communities and alternative file-sharing platforms, or when leaking sensitive information to (social/traditional) media, Anonymous does not simply aim at reaching potential "hackers" or specialist groups such as bloggers or journalists working within the digital sphere, but a wider group of individuals - beyond the "digital divide." The YouTube videos "Anonymous Occupy Wall Street Call to Action" and "Operation Invade Wall Street - A Message to the People" illustrates this step, from inspirational/affective to instructive and applicable for a range of public actors and bodies. "[Voiceover] [...] We must share the truth through our social networks, by texting, instant/private messaging, posting, and blogging to our friends and relatives. We must take to the streets and speak of the truth in our coffee shops and mall outlets. [...] Share this call to action, and encourage others to do the same."

This instruction is meant literally and its message is traditional. Through the rhetoric of "truth" as in opposition to the mainstream media narrative, "we" must speak of the whole story, i.e., not only of the issues framed by state or corporate media "in our coffee shops and mall outlets" (ibid.). In this sense, it is (or can be) enough that someone in the group has seen visible evidence of police brutality say, posted on YouTube (e.g., as the examples above exhibits), and then communicated this action to friends "outside" of the digital. This is not to say that there is a direct link between visual information and action, but rather that it is not an imperative to have direct access to the Internet to be informed about what is circulat-

http://i.huffpost.com/gen/1172078/thumbs/o-TURKEY-PROTESTS-WOMAN-IN-RED-570.jpg?6 (accessed August 30, 2013).

56 http://www.youtube.com/watch?v=VqWdyM91hFA.

57 Anonymous Occupy Wall Street Call to Action, http://www.youtube.com/watch?v=8IrGZnKf888 (accessed August 30,2013$)$. 
ing online. When WikiLeaks revealed the "collateral murder" video and/or when U.S. soldiers document and post individual war actions without authority through YouTube or Instagram, etc., words, pictures and, naturally, opinions start to emerge, and actions may follow, also "offline."."

In the video "Operation Invade Wall Street - A Message to the People" (2011), Anonymous takes this instructive function further when providing information on how to participate in direct DDoS attacks (see, e.g., http://www.youtube.com/watch?v=L_gmdRc5fGQ), or providing an interactive option to remix/re-edit the video (see for example, http://www.youtube.com/editor\#). That is, a possibility to take part in the audiovisual communications of the movement by creating a new version to publish online, accompanied with the following soundtrack (music and voiceover): "We are taking to the streets to show the wealthy elite that we, the $99 \%$, are no longer going to grease the gears of this abhorrent system. The lifeblood of the country is the working class, without it our people and our economy will crumble. [...] Our government has granted hefty tax exemptions to the rich at the cost of our social services. [...] You have complained that something needs to be done. You now have an opportunity to make a difference. Join the protests. [...] This is our movement. This is your moment." 59

As can be read from the voiceover, the narrative is highly dramatic/communicated in a personal style (appealing to a community of resistance against social injustice), and inspiring at once ("you have complained that something needs to be done; you now have an opportunity to make a difference"). And through this audio backdrop, the user interested in remixing the video can add new visuals and take part in the movement by spreading the communication further via YouTube or other digital platforms. Or by physically taking to the streets to join the OWS protests or be part in Anonymous's direct (DDoS) actions. The most important question remains however: Do any of these actions have long-term effects? To try to answer this question, we elaborate on Anonymous as a community of hope, lulz and affect.

\subsection{Lulz and Affect}

Many Anonymous actions seem to come about for a combination of political reasons, intimately connected with doing stuff (just) "for the lulz." For Anonymous, there is, hence, no opposition between the lulz and political engagement. The lulz can, as we suggest, (even if connected to an internal sphere of "recognition" and language within the Anonymous movement) also be understood as the (forbidden) pleasure or joy of fighting for something meaningful, the passion of (political) struggle (cf. Mouffe, 2013; 2005; Mouffe in Zournazi, 2002, e.g.). The pursuit of joy is, potentially, also a hope for social change. That is, not only pleasure for the sake of pleasure itself.

According to Coleman (2013b, 217), operation "HBGary" led to a feeling of empowerment among the followers of Anonymous. HBGary was a private security firm that claimed to have discovered the identities of a number of significant Anonymous hackers. Anonymous responded by breaking into the HBGary servers and "trolling," i.e., hacking into the Twitter account of the company's CEO and used it for provocative purposes. As a result of the HBGary hack, Anonymous found evidence "which outlined how HBGary, in conjunction with the U.S. Chamber of Commerce, Bank of America, and other security companies, might undermine WikiLeaks by submitting fake documents to the site. [...] What started with retaliatory trolling ended up exposing what seemed to be a conspiracy so damning that members of Congress called for an investigate committee (ibid.)."

The accumulation of cultural capital, i.e., the accumulation of "successful hacks," produced a sense of counter-power and showed how the pursuit of a rational political goal could be very well mixed with "trolling" and/or "the lulz," here viewed in the context of "the joy of

${ }^{58}$ Essentially, the online actions of Anonymous, LulzSec, Wikileaks and others, as stated by Anonymous associative "Topiary," bring "[a]ttention to the idea that actions taken online can have a major impact in real life - linking the two realities" (Topiary interviewed by Ryan Gallagher in The Guardian, July 14, 2011), http://www.theguardian.com/technology/2011/jul/14/why-lulzsec-decided-to-disband (accessed August 30, 2013).

59 http://www.youtube.com/watch?v=L_gmdRc5fGQ (accessed August 30, 2013). 
resistance;" the pleasure of challenging, and get access to, established power structures by breaking into "secure" servers/leaking data containing information of public interest. Eventually, this accumulation of cultural capital, too, works towards the construction of a radi$\mathrm{cal} /$ social imaginary: If power can actually be challenged, re-evaluations of current political situations are also possible. Therefore, we must not regard the actions of Anonymous from a strict cause-and-effect perspective. The consequences of its actions must rather be considered in the light of what Kristeva labels as a "symbolic deconstruction" of Western political fantasy - the hegemonic discourses in circulation - via a reinvigoration of critical thought, and/or the "symbolic renewal" of (communities of) hope. ${ }^{60}$

In this paper, we have elaborated on affect as a potential and driving force for social mobilisation and action; an opportunity to contribute to, and feel empowered by, an alternative worldview. Participating in revolutionary movements - the hope of equality - or the fight for justice - might give a sense of purpose to one's life and inspire to action. As for life, the lulz, translated into "joy" ("joyful passions" or "hope") are then basically fundamental for rebellion. Without joy, or the fantasy of hope, we cannot, imagine an "alternative" to - and less revolting against - a given political situation. Here, the lulz is, also, a power, a force necessary for action, inspiring others to act.

Evidently, the hacks committed by Anonymous will not replace the prevailing political and economic system with a brand new alternative. But the accumulation of affective capital makes Anonymous, and the ones that associate themselves with ideas close to the political project of Anonymous, believe that there exists, at least, a form of capacity among Anonymous to reveal certain information that can fuel a critical understanding of power relations; and henceforth, there is hope (for social change) ${ }^{61}$ Moreover, in this (lulzy/joyful) passion for change, significant (physical and virtual) communities are formed. Affect bears a potential for social mobilisation; to inspire or be inspired, to act or inspire others to act; to expand by affecting others (with joy, passion, or, hope). This is, as we argue, the affective strength of the body of Anonymous; the intersection, connection and growth of particles (hacktivism, audiovisual communications, geopolitical actions, international relations, etc.) and its capacity to affect and be affected.

However, the relation between affect or "political passion" and resistance is not unique for Anonymous, but the global geopolitical potential of Anonymous may distinguish itself from other social movements by the integration of organized but formally "leaderless" hacktivism and direct web-action (with real-time effects), with physical street action. The "lulz" and the "trolling" language/aesthetics of Anonymous, which also suits the media logic when reporting on spectacular hacks, are thus an integral part of this (underground) Internet popular culture which extends to physical street actions (and vice versa). In sum, this seems to be a reason for Anonymous's politically affective potential in mobilising people to engage in public debate; cognitively, affectively and physically. ${ }^{62}$

In specific regard to the political aesthetics of Anonymous, this affective language is also framed in the Anonymous YouTube videos extensively by sound effects (distorted voice effect) and a dramatic voiceover narrative ("there has never been a more exciting time to be alive; fight greed, corruption and corporate control of our democracy," e.g.), often accompanied by suggestive/emotional pieces of music. ${ }^{63}$ These sound aesthetics are often edited together with reframes of archive footage, showing civilian victims filtered through the Anonymous aesthetic package. The YouTube videos are hence basically conventional, like remastered versions of the TV news. Spectacular images led forward by a voiceover narrative. But clear and, in this case also stylish (and somewhat populist).

These (hybrid) archive images serve then, simultaneously, both as "visible evidence" of traumatic encounters and as affective visual information (cf. Ferrada Stoehrel, 2013a,

${ }^{60}$ That is, the social/radical imaginary. See also Kristeva's "Joyful Revolt" (Zournazi, 2002, 75-76).

${ }^{61}$ Cf. Hage's reading of Bourdieu in: Zournazi, 2002.

${ }^{62}$ Engaging in specific Internet action is of course different from traditional (physical) direct action but both are complementary and feed off each other (suitable for different purposes and actors).

${ }^{63}$ See, e.g. Anonymous - Message to Occupy the World, http://www.youtube.com/watch?v=VqWdyM91hFA (accessed August 30, 2013). 
2013b). The Anonymous audiovisual producers are, from all appearances, then highly aware of the complexity of the image and do not consider representation as unambiguous (epistemologically or ontologically). On the contrary, the aesthetic-affective construct (the dramaturgy) of the Anonymous YouTube videos recognizes the dialectical relationship that exists between the cognitive and the affective in our experience of the visual - and makes it work for political and engaging purposes. That is, even if the "mediated suffering" shown by Anonymous is sometimes merely "performative" (and even melodramatic), the mediation is constructed in order to lead the spectator towards action (cf. Chouliaraki, 2006).

It is thus not difficult to trace the influence of popular culture - may it be through the genre of traditional fiction film, video game aesthetics or the melodramatic audiovisual narrative of the TV-news - of the Anonymous producers. In this sense, Anonymous exploit the aesthetics - the technical-dramaturgical conventions - of popular culture in order to create identification among viewers and a counter-narrative to the system to which they belong (cf. Terdiman's notion of "image culture as a field of struggle," 1989; i.e., where the production and reframing of signs and discourses form part of a series of historical power/knowledge struggles). Hence, neither the Anonymous tendency toward spectacle nor the "lulz," are fully ends in themselves, but rather, as the use of the Guy Fawkes mask suggests, Anonymous arises from the logics of contemporary popular (Internet) culture and the genres of performance where even political action/resistance is portrayed in the light of entertainment or populism to make impact.

Or, to say it in simplified terms, Anonymous employs a mainstream populist format to communicate an alternative content. Massumi $(2002,234)$ writes, "It seems to me that alternative political action does not have to fight against the idea that power has become affective, but rather has to learn to function itself on that same level - meet affective modulation with affective modulation." From this perspective it seems that counter-hegemonic conducts needs to be somewhat populist, or at least capable of inspiring/circulate this economy of affect ("joyful passions," etc.), in order to be effective (attract others) - or no one will join the movement. Taken together, Anonymous provides potential participants with something extra than just a rational political reason to join the Anonymous idea, but also - and this is crucial a promised "joyful" experience; and an opportunity to join an "epic" community, to feel recognised or to be listened to. The moral or rational focus on "the political," the call for civil rights, anonymity, free speech, etc., is thus not enough for mobilising resistance. In our view, if social change is about to be effective, (Western) social movements are also in need of an aesthetic and affective policy. This means a strategy where different identities can feel attracted to the idea of becoming part of a ("cool," "sexy" or "epic") community, and this goes (very much) via symbolic/visual strategies of engagement, i.e., not a political communication based (only) on a rational/moral human rights discourse.

\section{Conclusions}

Obviously, not all actions of Anonymous have a rational political purpose and some, or even many of them are surely merely motivated just "for the laughs." But within the laughs (the lulz), there is also a space for passion, a (joyful) passion for social change. What the actions of Anonymous do, then, is to use the hacktivist tactics and the digital aesthetics of protest to influence; to affect other bodies, connecting on- and offline communities with an alternative sphere of affect and knowledge production in regard to the political economy.

The motto of Anonymous is that "even the smallest movement can change everything," i.e., that every single and particular operation made by a set of individuals (online) can have a larger impact on society (also offline) and the dominant rhetoric of democracy (a counternarrative of Western discourse regarding the practice of "preventive defence" as necessary for securing democracy, etc.). The Anonymous language is also different from traditional revolutionary movements. Rather than focusing on physical resistance, the political struggle here is about challenging the hegemonic discourses and the rights to access to specific distribution channels. Communication also makes use of humour, framed by the intertextual aesthetics (and populism) of popular culture. In other words, the (radical) political struggle of 
Anonymous is not just intellectual or physical; it is a form of passion including "the lulz," the act of "trolling," humour and joy - may it be for personal or for collective enjoyment. And, as Deleuze suggests in his Spinozan reading: "The passions that [...] [empower] us are those of joy, and our power of acting is increased or enhanced" $(1988,28)$. That is, the lulz works as an affective, political, force with a capacity of politically inspiring and affecting others (to desire, to hope; to act, to move). This joyful, lulzy, passion is reflected in the visuals of Anonymous. But again, it is not a question of choosing the lulz over the rational; it is the combination of affective and cognitive processes that characterises the political actions. This is the political strength of Anonymous, and their (audio)visuals.

At the intersection of hacking and aesthetic/political strategies, the visual narrative of Anonymous follows, hence, a similar structure: together with a dramatic voiceover and an intertextual (and lulzy) frame, the YouTube videos and graphics/propaganda posters often have embedded links to IRC chats, online forums, press releases or instructions on how to avoid Internet surveillance (and/or instructions on how to participate in DDoS attacks). In terms of strategy, the digital aesthetics of Anonymous as a protest movement can be summarised as follows:

(1) The whole aesthetic profile developed by Anonymous through their different forms of knowledge production includes intertextual references to popular culture and harnesses the logic of today's media system. When deployed in specific hacking actions, the aesthetic elements - such as the YouTube videos of Chaplin, the Anonymous Asteroids game or the Guy Fawkes mask, etc. - appear as "tags," i.e., as marks that function as visible evidence of the hack (this goes back to the same idea as the one behind graffiti tags like "Kilroy was here" etc.). In this sense, the hacktivist aesthetics provide the mainstream media with spectacular images when reporting on Anonymous (this is the "PR tactics" of Anonymous) and at the same time, under the best of circumstances, it may inspire political reflection and make the political debates on state-corporate surveillance and the very notion of "freedom" themselves more attractive, and available for potential identification. At worst, the Anonymous aesthetics may seem populist (spectacular, but speculative) and shallow.

(2) From a strategic PR-perspective, even if the Anonymous aesthetics may be of a "prankish" nature they are, as a whole, a strategy aiming to generate myth (building status as an epic movement). Hence, what could be seen as a classic computer hack, or even just as a naïve prank, may also include other goals and effects connected to the "branding" of Anonymous.

(3) Not all of Anonymous's (audio)visuals are directly connected to acts of hacking. A fundamental part of the Anonymous aesthetics is focused on visually inspiring a political conscious by disrupting or reframing the dominant narratives of mainstream media. By taking news images from large media organisations and putting them into a new visual context together with the Anonymous aesthetic filter characterised by the distorted computer voiceover, Anonymous logo and layers of visual effects and music - a power struggle for the control of signs and meaning is set in motion. In a similar vein, Anonymous works as an "alternative media" claiming access to visual truths by providing and distributing forms of citizen journalism, visual leaks and grassroots visuals that compete with the visual narrative of state and commercial media.

(4) By using the Anonymous's graphic profile, individual political actions become part of the Anonymous collective and are provided with authority (gained from the symbolic capital accumulated throughout the history of "successful" hacks of Anonymous).

As final words, we would like to point out that, due to the illegal nature of the movement, Anonymous presents a lack of transparency in their structure as well as in the process of decision-making. The process of "hacking" or leaking classified information is also problematic since Anonymous may put civilians in different forms at risk. However, when connected to political dissent or the whistleblowing culture, Anonymous are, as we suggest, critical in their capacity to challenge (or, to put it in Anonymous terms, "troll") hegemonic discourses.

\section{References}

Ahmed, Sara. 2010. The Promise of Happiness. Durham: Duke University Press. 
Bröckling, Ulrich, Krasmann, Susanne and Lemke, Thomas, eds. 2011. Governmentality: Current Issues and Future Challenges. New York: Routledge.

Bourdieu, Pierre. 1986. The Forms of Capital. In Handbook of Theory and Research for the Sociology of Education, edited by John G. Richardson. New York, NY: Greenwood.

Coleman, Gabriella. 2011. Anonymous: From the Lulz to Collective Action. The New Everyday: A MediaCommons Project, April 6. Accessed August 30, 2013.

http://mediacommons.futureofthebook.org/tne/pieces/anonymous-lulz-collective-action

Coleman, Gabriella. 2013b. Anonymous and the Politics of Leaking. In Beyond WikiLeaks: Implications for the Future of Communications, Journalism \& Society, edited by Benedetta Brevini, Arne Hintz and Patrick McCurdy. Basingstoke: Palgrave Macmillan.

Chomsky, Noam. 2012. Occupy. London: Penguin.

Chouliaraki, Lilie. 2006. The Spectatorship of Suffering. London: Sage.

Cosgrove, Stuart. 1984/2002. The Zoot-Suit and Style Warfare. In Cultural Resistance: A Reader, edited by Steven Duncombe. London: Verso.

Dean, Mitchell. 2010. Governmentality: Power and Rule in Modern Society. London: Sage publications.

Deleuze, Gilles and Guattari, Felix. 1988. A Thousand Plateaus. London: Athlone.

Deleuze, Gilles. 1990. Expressionism in Philosophy: Spinoza. New York: Zone Books.

Deleuze, Gilles. 1988. Spinoza: Practical Philosophy, translated by Robert Hurley. San Francisco: City Lights.

Ferrada Stoehrel, Rodrigo. 2013a. The Legal Image's Forgotten Aesthetics. International Journal for the Semiotics of Law 26 (3): 555-577.

Ferrada Stoehrel, Rodrigo. 2013b. Politics, Pleasure, Violence: Swedish Defence Propaganda in Social Media. MedieKultur. Journal of Media and Communication Research 29 (55): 21-42.

Foucault, Michel. 1991. The Foucault Effect: Studies in Governmentality, edited by Graham Burchell, Colin Gordon, Peter Miller. Chicago: University of Chicago Press.

Foucault, Michel. 1994. Confronting Governments: Human Rights. In Power: Essential Works of Foucault, 1954 -, 1984, volume 3, edited by James D. Faubion. London: Penguin.

Foucault, Michel. 2007. Security, Territory, Population: Lectures at the Collège de France, 1977-78, translated by Graham Burchell. Basingstoke: Palgrave Macmillan.

Hage, Ghassan. 2002. On the Side of Life - Joy and the Capacity of Being. In Hope: New Philosophies for Change, edited by Mary Zournazi. Annandale, NSW: Pluto Press.

Goodwin, Jeff, James M. Jasper and Francesca Polletta, eds. 2009. Passionate Politics: Emotions and Social Movements. Chicago: University of Chicago Press.

Harding, Jenniferand E. Deidre Pribram. 2004. Losing our Cool? Following Williams and Grossberg on Emotions. Cultural Studies 18 (6): 863-883.

Kristeva, Julia. 1984. Revolution in Poetic Language. New York, NY: Columbia University Press.

Kristeva, Julia. 2002. Joyful Revolt. In Hope: New Philosophies for Change, edited by Mary Zournazi. Annandale, NSW: Pluto Press.

Laclau, Ernesto \& Chantal Mouffe. 1985. Hegemony and Socialist Strategy: Towards a Radical Democratic Politics. London: Verso.

Lindgren, Simon. 2013. New Noise: A Cultural Sociology of Digital Disruption. New York, NY: Peter Lang.

Lynd, Staughton. 2012. Preface. In Dreaming in Public: The Building of the Occupy Movement, edited by Amy Schrager Lang and Daniel Levitsky. Oxford: New Internationalist.

Massumi, Brian. 2002. Navigating Movements. In Hope: New Philosophies for Change, edited by Mary Zournazi. Annandale, NSW: Pluto Press.

Mitchell, William J. T., 2013. Preface \& Inquiries in Disobedience. In William J. T. Mitchell, Bernard E. Harcourt, and Michael Taussig. 2013. Occupy: Three Inquiries in Disobedience. Chicago: University of Chicago Press.

Mouffe, Chantal. 2013. Agonistics: Thinking the World Politically. London: Verso Books.

Mouffe, Chantal. 2005. On the Political. London: Routledge.

Nadesan, Majia Holmer. 2008. Governmentality, Biopower, and Everyday Life. New York: Routledge.

Olson, Parmy. 2012. We are Anonymous: Inside the Hacker World of LulzSec, Anonymous, and the Global Cyber Insurgency. New York, NY: Little, Brown and Co.

Reed, T.V. 2013. Digitizing the Arts of Protest. In Mobilizing Ideas, June 10. Accessed August 30, 2013. http://mobilizingideas.wordpress.com/2013/06/10/digitizing-the-arts-of-protest/ (10:06:2011, 7.00 AM). 
Rodríguez, Clemencia. 2011. Citizens' Media against Armed Conflict: Disrupting Violence in Colombia. Minneapolis, MN: University of Minnesota Press.

Rone, Julia. 2012. The Seducer's Net: Internet, Politics and Seduction. In Digital Cultures and the Politics of Emotion: Feelings, Affect and Technological Change, edited by Athina Karatzogianni and Adi Kuntsman. Basingstoke: Palgrave Macmillan.

Sontag, Susan. 1994. Waiting for Godot in Sarajevo. Performing Arts Journal 16 (2): 87-106.

Spinoza, Baruch. 1982. The Ethics. Indianapolis, IN: Hackett Publishing Company.

Terdiman, Richard. 1989. Discourse/Counter-Discourse: The Theory and Practice of Symbolic Resistance in Nineteenth-Century France. Ithaca, NY: Cornell University Press.

Vitale, Mike. 2012. In We Are Legion: The Story of the Hacktivists. Documentary film directed by in Brian Knappenberger.

Williams, Caroline. 2007. Thinking the Political in the Wake of Spinoza: Power, Affect and Imagination in the Ethics. Contemporary Political Theory 6 (3): 349-369.

Žižek, Slavoj. 1997. The Plague of Fantasies. London: Verso.

Žižek, Slavoj. 2002. For They Know Not What They Do: Enjoyment as a Political Factor. London: Verso.

Žižek. Slavoj. 2007. How to Read Lacan. New York and London: Norto.

Williams, Raymond. 1979. Politics and Letters: Interviews with New Left Review. London: New Left Books.

\section{Web/news articles}

Claiborne, Clay. 2011. Anonymous plans Op Swift Assist in Tunisia. Daily Kos, January 20. Accessed August 30, 2013. http://www.dailykos.com/story/2011/01/20/937534/-Anonymous-plans-Op-SwiftAssist-in-Tunisia\# (20:01:2011, 01:06 PM PST).

Coleman, Gabriella. 2013a. Geeks are the New Guardians of our Civil Liberties. MIT Review, February 4. Accessed August 30, 2013. http://www.technologyreview.com/news/510641/geeks-are-thenew-guardians-of-our-civil-liberties/.

Committee to Protect Journalists. 2011. As Ben Ali's Regime Falls, 3 Tunisian Journalists Freed, January 14. Accessed August 30, 2013. http://cpj.org/2011/01/as-ben-alis-regime-falls-3-tunisianjournalists-fr.php (14:01:2011, 8:51 PM ET).

Erdogan, Recep Tayyip. 2013a. Twitter is a Troublemaker: Turkish PM. Daily News, June 2. Accessed August 30, 2013. http://www.hurriyetdailynews.com/twitter-is-a-troublemaker-turkish-pm--.aspx?pagelD $=238 \&$ nID $=48084 \&$ NewsCat ID $=338$

Erdogan, Recep Tayyip. 2013b. Social Media and Opposition to Blame for Protests, says Turkish PM. The Guardian, June 3. Accessed August 30, 2013.

http://www.guardian.co.uk/world/2013/jun/02/turkish-protesters-control-istanbulsquare?CMP=twt gu

Enzer, Georgina. 2011. Anonymous Hacks Syrian Government Website. ITP.net, August 8. Accessed August 30, 2013. http://www.itp.net/585719-anonymous-hacks-syrian-governmentwebsite\#.Uick1M1r6wo

Gallagher, Ryan. 2011. Why Hacker Group LulzSec Went on the Attack. The Guardian, July 14. Accessed August 30, 2013. http://www.theguardian.com/technology/2011/jul/14/why-lulzsec-decidedto-disband (07:14:2011, 20.30 BST).

Harrison, Sarah. 2013. Statement by Sarah Harrison. Wikileaks, November 6. Accessed December 12, 2013. http://wikileaks.org/Statement-by-Sarah-Harrison-on.html (6:11:2013, 18:30 CET).

Hastings, Michael. 2012. Exclusive: Homeland Security Kept Tabs on Occupy Wall Street. Rolling Stone, February 28. Accessed August 30, 2013. http://www.rollingstone.com/politics/blogs/nationalaffairs/exclusive-homeland-security-kept-tabs-on-occupy-wall-street-20120228 (28:02:2012, 6:55 PM ET).

Hopkins, Curt. 2013. Anonymous Claims it Wasn't Behind Operation Last Resort. The Daily Dot, February 01 . Accessed August 30, 2013. http://www. dailydot.com/news/anonymous-operation-lastresort-hoaxl.

Kanalley, Craig and Bialer, Jake. 2011. Anonymous Internet Users Team Up To Provide Communication Tools For Egyptian People. The Huffington Post, January, 19. Accessed August 30, 2013. http://www.huffingtonpost.com/2011/01/29/anonymous-internet-egypt_n_815889.html (29:01:2011, 07:30 PM ET).

Kessler, Robert. 2013. Anonymous Hacks Department of Justice Website, Threatens to Launch "Multiple Warheads." Gawker, January 26. Accessed August 30, 2013. 
http://gawker.com/5979203/anonymous-hacks-department-of-justice-website-threatens-to-launchmultiple-warheads (26:01:2013, 11:21 AM).

Knappenberger, Brian. 2012b. In Faces, Some Masked, of Anonymous, by Nina Metz. Chicago Tribune, December 06. Accessed August 30, 2013. http://articles.chicagotribune.com/2012-1206/entertainment/ct-mov-1207-chicago-closeup-20121207_1_guy-fawkes-mask-online-donationscontroversial-website.

Leyden, John. 2013. Anons Hack Asteroids into US DoJ Website in Swartz Death Protest. The Register, January 28. Accessed August 30, 2013.

http://www.theregister.co.uk/2013/01/28/anon_doj_hack_swartz_protest/ .

Marshall, Andrew G. 2012. The Shocking Amount of Wealth and Power Held by $0.001 \%$ of the World Population. AlterNet, June 12. Accessed August 30, 2013. http://www.alternet.org/economy/globalpower-elite-exposed.

Meek, James G., Ferran, Lee, and Phillip, Abby. 2013. On the Hunt for the NSA Wiretapping Leaker. $A B C$ News, June 7. Accessed August 30, 2013. http://abcnews.go.com/Blotter/hunt-nsawiretapping-leaker/story?id=19348771.

nwlinux. 2011. Anonymous Delivers Christmas Eve Hack to STRATFOR, December 24. Accessed August 30, 2013. http://nwlinux.com/anonymous-delivers-christmas-eve-hack-to-stratfor/ .

Puppetworld Post. 2011. Tunisia Is The First Anonymous Revolution, January 22. Accessed August 30, 2013. http://www.puppet99.com/?p=58; http://emajmagazine.com/2011/01/23/young-tunisian-icant-stop-smiling .

Protalinski, Emil. 2012. Time Magazine Readers Name Anonymous "Most Influential Person." ZDNet, April 18. Accessed August 30, 2013. http://www.zdnet.com/blog/security/time-magazine-readersname-anonymous-most-influential-person/11603 (18:04:2012, 11:38 GMT).

Reitman, Janet. 2012. The Rise and Fall of Jeremy Hammond: Enemy of the State. Rolling Stone, July 12. Accessed August 30, 2013. http://www.rollingstone.com/culture/news/the-rise-and-fall-ofjeremy-hammond-enemy-of-the-state-20121207?page=2 (12:07:2012, 1:20 PM ET).

RT USA. 2011. Anonymous Details Stratfor Christmas Hack, December 12. Accessed August 30, 2013. http://rt.com/usa/anonymous-stratfor-barrett-firm-777/ (27:12:2011, 20:08).

Somaiya, Ravi. 2011. Hackers Shut Down Government Sites. The New York Times, February 2. Accessed August 30, 2013. http://www.nytimes.com/2011/02/03/world/middleeast/03hackers.html? r=0 .

Sparrow Media. 2013. Jeremy Hammond Pleads Guilty to Stratfor Leak, Faces Harsh Sentence for Online Protest: Press Release \& Jeremy's Statement, May 28. Accessed August 30, 2013. http://www.sparrowmedia.net/2013/05/jeremy-hammond-plea-deal/ (28:05:2013 8:21 AM).

Time. 2012. The 2012 TIME 100 Poll. Accessed August 30, 2013. http://content.time.com/time/specials/packages/article/0,28804,2107952_2107959,00.html .

Wagenseil, Paul. 2011. "Hacktivists" Launch Second Attack on Egypt. NBC News, Mars 2. Accessed August 30, 2013. http://www.nbcnews.com/id/41407082/ns/technology and sciencesecurity/t/hacktivists-launch-second-attack-egypt/\#.UejrS81r6wo (2:3:2011 10:39 AM ET).

\section{Press Releases and Reports}

Anonymous. 2013. \#opSOTU. Accessed August 30, 2013. http://anonnews.org/press/item/2111/

ITU. 2013. ICT Data for the World, by Geographic Regions and by Level of Development (Excel). Accessed August 30, 2013. http://www.itu.int/en/ITU-D/Statistics/Pages/stat/default.aspx .

Zato, Carolina, Alejandro Sanchez, Gabriel Villarrubia, Sara Rodriguez, Manuel Corchado and Javier Bajo. 2012. Platform for Building Large-Scale Agent-Based Systems. In IEEE Conference on Evolving and Adaptive Intelligent Systems (EAIS), May 17-18, 69-73.

Zhong, Rui and Guangxue Yue. 2010. DDoS Detection System Based on Data Mining. In Proceedings of the Second International Symposium on Networking and Network Security, April 2-4, 062-065.

\section{About the Authors}

Rodrigo Ferrada Stoehrel

is a PhD candidate at the Department of Culture and Media Studies, Umeå University, Sweden. His research has a focus on visual culture, power, affect and discourses of security. Rodrigo is specifically interested in judicial audio-visual practices and truth-claiming images, visual rhetorics, digital (political) aesthetics, hacker culture and counter-narratives/culture as a field of struggle. He is also a journalist/film maker (director, editor and photographer). 


\section{Simon Lindgren}

is a Professor of Sociology at Umeå University, Sweden. He researches digital culture with a focus on how new media audiences navigate the border landscape between the new potentials for participation and activism on the one hand, and the risks for exclusion and exploitation on the other. Simon is actively taking part in developing theoretical as well as methodological tools for analysing discursive and social network aspects of the emerging new media landscape. He has published internationally on themes like hacktivism, digital piracy, citizen journalism, subcultural creativity, popular culture and visual politics. 